OPEN ACCESS

Edited by:

Mariusz Skwarczynski,

The University of Queensland,

Australia

Reviewed by:

Valentin A. Pavlov,

Northwell Health, United States

Daniel Carvalho Pimenta,

Butantan Institute, Brazil

${ }^{*}$ Correspondence: Lenin Pavón

Ikuriaki@imp.edu.mx

Sonia Mayra Pérez-Tapia mayra.perez@udibi.com.mx

tORCID:

Luis Vallejo-Castillo orcid.org/0000-0002-9532-3472 Liliana Favari orcid.org/0000-0003-4414-966X

Said Vázquez-Leyva orcid.org/0000-0003-2625-1230

Gabriela Mellado-Sánchez orcid.org/0000-0002-8299-5958

Zaira Macías-Palacios orcid.org/0000-0002-9040-7378

Leonardo López-Juárez orcid.org/0000-0002-5483-8197

Luis Valencia-Flores orcid.org/0000-0002-4235-5024

Emilio Medina-Rivero orcid.org/0000-0001-8862-1378

Rommel Chacón-Salinas orcid.org/0000-0002-4500-0253 Lenin Pavón orcid.org/0000-0002-6067-6868

Sonia Mayra Pérez-Tapia orcid.org/0000-0002-2818-8522

Specialty section:

This article was submitted to Experimental Pharmacology and Drug Discovery, a section of the journal

Frontiers in Pharmacology

Received: 06 July 2020 Accepted: 16 September 2020 Published: 07 October 2020

\section{Sequencing Analysis and} Identification of the Primary Peptide Component of the Dialyzable Leukocyte Extract "Transferon Oral": The Starting Point to Understand Its Mechanism of Action

\author{
Luis Vallejo-Castillo ${ }^{1,2,3 \dagger}$, Liliana Favari ${ }^{2 \dagger}$, Said Vázquez-Leyva ${ }^{1,3 \dagger}$, \\ Gabriela Mellado-Sánchez ${ }^{1,3+}$, Zaira Macías-Palacios ${ }^{1,3+}$, Leonardo E. López-Juárez ${ }^{1,3 \dagger}$, \\ Luis Valencia-Flores ${ }^{1,3+}$, Emilio Medina-Rivero ${ }^{1 \dagger}$, Rommel Chacón-Salinas ${ }^{4 \dagger}$, \\ Lenin Pavón ${ }^{5 * t}$ and Sonia Mayra Pérez-Tapia ${ }^{1,3,4 * t}$
}

1 Unidad de Desarrollo e Investigación en Bioprocesos (UDIBI), Escuela Nacional de Ciencias Biológicas, Instituto Politécnico Nacional, Mexico City, Mexico, ${ }^{2}$ Departamento de Farmacología, Centro de Investigación y de Estudios Avanzados del IPN, Ciudad de México, Mexico, ${ }^{3}$ Laboratorio Nacional para Servicios Especializados de Investigación, Desarrollo e Innovación $(I+D+i)$ para Farmoquímicos y Biotecnológicos (LANSEIDI-FarBiotec-CONACyT), Escuela Nacional de Ciencias Biológicas, Instituto Politécnico Nacional, Mexico City, Mexico, ${ }^{4}$ Departamento de Inmunología, Escuela Nacional de Ciencias Biológicas, Instituto Politécnico Nacional, Mexico City, Mexico, ${ }^{5}$ Laboratorio de Psicoinmunología, Dirección de Investigaciones en Neurociencias, Instituto Nacional de Psiquiatría Ramón de la Fuente., Mexico City, Mexico

"Transferon Oral" is a peptide-derived product with immunomodulatory properties obtained from the lysis and dialysis of human buffy coat. Its active pharmaceutical ingredient, generically known as Dialyzable Leucocyte Extract, is a mixture of peptide populations with reproducible proportions among batches. "Transferon Oral" modulates IFN- $\gamma$, TNF- $\alpha$, and IL- 6 and increases the survival rate in a herpes infection murine model when oropharyngeally $(\mathrm{ORO})$ administered, which correlate with clinical observations where "Transferon Oral" is used as a therapeutic auxiliary in inflammatory diseases. Notwithstanding, how a peptide-derived product elicits systemic modulation of cytokines when ORO administered remains unclear. To shed light on the pharmacology of "Transferon Oral" its peptide components must be known. Ten "Transferon Oral" batches were sequenced by mass spectrometry and the intact peptides were identified. The most abundant peptides were the monomeric human Ubiquitin (Ub), a globular low-molecular mass protein, and an Ub variant which lacks the two-terminal Gly (Ub-GG). Recombinant Ub prevented murine death when ORO administered in a herpes infection murine model. Besides, the percentage of survival increased in groups treated with Transferon Oral+Ub and decreased in groups treated with Ub-depleted "Transferon Oral" respect to the group treated with "Transferon Oral" only. Our findings indicate that the biological properties of "Transferon Oral" are partially associated to the Ub content. They suggest that Ub may activate its extracellular receptor (CXCR-4) in the stomach 
eliciting systemic immunomodulatory effects via vagus nerve. This is the first report that identifies an active component of "Transferon Oral" with the potential for the development of oral peptide immunomodulators.

Keywords: Transferon, human dialyzable leukocyte extracts, MS sequencing, immunomodulatory drugs, oral peptides, monomeric ubiquitin

\section{INTRODUCTION}

Immunotherapy involves the stimulation, enhancement, suppression, or desensitization of the immune response to treat malignancies. Among the immunotherapeutics, stand out the human dialyzable leukocyte extracts (hDLE) which are composed of a low-molecular mass peptide mixture with immunomodulatory properties obtained from the lysis of mammalian cells. Since their first description, made in 1949 by Henry Sherwood Lawrence who also coined the term "Transfer factor" (Lawrence, 1949), dialyzable extracts have been developed in some countries such as China, Czech Republic, Cuba, the USA, and Mexico, as auxiliary drugs to treat immune system-related diseases (Ojeda et al., 2005; Zhou et al., 2013; Cardoso et al., 2017). However, the biological effects of these cellular extracts have been controversial due to the variability of the peptide content among products, which is highly dependent on their cellular origin and the manufacturing method.

In the 60s, Dr. Sergio Estrada-Parra developed and started the laboratory-scale production of an hDLE at the National Polytechnic Institute (IPN for its Spanish acronym) in Mexico, which derived into a pharmaceutical product called "Transferon Oral." This product is obtained from lysed human buffy coats by freeze/thaw cycles and peptides with a size less than $10 \mathrm{kDa}$, the active pharmaceutic ingredient (API) of "Transferon Oral", are separated by dialysis and ultrafiltration (Medina-Rivero et al., 2016). "Transferon Oral" has been developed as a complex drug owing to its intricate composition, i.e., its peptides components have been regarded as a unique population, and the physicochemical behavior of the peptide fraction has been determined in several batches using a large battery of analytical techniques, such as SDS-PAGE, UPLC, MS, and NMR (Crommelin et al., 2015). These analyses have evinced the high reproducibility of the peptide components of "Transferon Oral" among all batches, despite its complex composition (MedinaRivero et al., 2014; Medina-Rivero et al., 2016; Vazquez-Leyva et al., 2019).

"Transferon Oral" has been used as an auxiliary treatment in patients with inflammatory diseases (Hernandez et al., 2013; Homber et al., 2015). "Transferon Oral" improves resolution of infectious diseases by increasing the number of systemic IFN- $\gamma$ cells in ocular fungal keratitis and enhances the survival of pediatric patients with sepsis by lowering $C$ reactive protein (CRP), rising increases total lymphocyte numbers and decreasing total neutrophil count (Santacruz-Valdes et al., 2010; Castrejon Vazquez et al., 2019). Besides, Transferon ${ }^{\circledR}$, the parenteral version of "Transferon Oral" increases IFN- $\gamma$ levels in serum and favors the clinical course in patients with herpes zoster infection when administered by subcutaneous route (EstradaParra et al., 1998).

Several models have been developed to understand the signaling pathways by which "Transferon Oral" elicits its therapeutic effect. Regarding in vitro models, "Transferon Oral" increases the expression of CD80/CD86 and IL-6 levels in LPS-stimulated macrophage-like THP-1 cells, whereas it induces the differentiation of IFN- $\gamma$-producing NK CD56 $+\mathrm{CD} 16+\mathrm{CD} 11 \mathrm{c}+$ cells from CD34+ progenitor cells obtained from human umbilical cord (Ramirez-Ramirez et al., 2016; Jimenez-Uribe et al., 2019). On the other hand, "Transferon Oral" (1-25 $\mu \mathrm{g} / \mathrm{kg})$ reduces tumour growth and metastasis in a murine prostate cancer model, while in Herpes Simplex Virus type 1 (HSV-1) infection murine model "Transferon Oral" decreases the bloodstream levels of TNF- $\alpha$ and IL- 6 and increases IFN- $\gamma$ levels and the percent of survival when oropharyngeal administered (ORO) (Salinas-Jazmin et al., 2015; Hernandez-Esquivel et al., 2018). Nevertheless, the information provided by these models is no enough to explain how a peptide extract can modulate the immune system when administered by an enteral route. In this sense, it is essential to identify the peptide components of "Transferon Oral", at least the most abundant, to understand the bases of the immunomodulatory properties of this blood-derived product.

The aim of this work was to the sequence of peptide components of Transferon through mass spectrometric techniques, to identify of the primary peptide component and to evaluate its relevance to the immunomodulatory properties of "Transferon Oral" using in a murine model of HSV-1 infection. Finally, we analyzed this information to propose a new hypothesis for the immunomodulatory effects of "Transferon Oral", which will be further studied in depth later.

\section{MATERIALS AND METHODS}

\section{Analytical Samples}

"Transferon oral," henceforth only Transferon, was used in this study. All Transferon batches were manufactured by PharmaFT Laboratory (Mexico City, Mexico) using a standardized method described elsewhere (Medina-Rivero et al., 2016). Briefly, human buffy coats were acquired from certified blood banks, and the cell content was disrupted by applying freezethaw cycles. The lysate was dialyzed through a $12-\mathrm{kDa}$ membrane, and the permeate was filtrated by a $10-\mathrm{kDa}$ cartridge. The obtained solution was diluted to $0.4 \mathrm{mg} / \mathrm{mL}$ using water for injection (Pisa Laboratories; Jalisco, Mexico). Transferon batches were subjected to a quality control 
analysis, which included sterility, identity, $\mathrm{pH}$, endotoxin content, relative density, total protein content, identity, and potency. All Transferon batches were kept at $-18^{\circ} \mathrm{C}$ until use and complied the acceptance criteria established by the manufacturer.

\section{MS De Novo Sequencing}

Transferon was de novo sequencing to identify the proteins that provide its peptide content. Ten Transferon batches (14G18, 14G19, 15A03, 15A04, 15C10, 15D11, 15D12, 15E14, 15F17, and 15G18) were sequencing by UCDavis Genome Center (CA, USA) using standardized methods. Briefly, Transferon samples were lyophilized using a FreeZone Dry System (Labconco; MO, USA), and $2 \mathrm{mg}$ of Transferon were cleaned using the ProteoExtract ${ }^{\circledR}$ Protein Precipitation Kit (Calbiochem; CA, USA) according to manufacturer's instructions. Samples were reconstituted in approximately $100 \mu \mathrm{L}$ of $6.0 \mathrm{M}$ urea (SigmaAldrich; SO, USA), reduced with 1-4 Dithiothreitol (SigmaAldrich) at $5 \mathrm{mM}$ and $37^{\circ} \mathrm{C}$ during $30 \mathrm{~min}$, and alkylated with iodoacetamide (Sigma-Aldrich) at $15 \mathrm{mM}$ and room temperature during $10 \mathrm{~min}$. Iodoacetamide was quenched by adding and excess of the reducing agent. Trypsin/Lys-C (Promega; WI, USA) was added in a 1:25 (enzyme:peptide) ratio an incubated at $37^{\circ} \mathrm{C}$ during $4 \mathrm{~h}$. Then, $550 \mu \mathrm{L}$ of $50 \mathrm{mM}$ ammonium bicarbonate buffer (Sigma-Aldrich) was added and the digestion continued overnight. Samples were desalted using Macro Spin Columns (The Nest Group; MA, USA) according to the manufacturer's instruction. Samples were recovered in a water:acetonitrile + formic acid solution (20\%:80\% + 0.5\%) (Thermo Scientific; MA, USA).

Samples were analyzed by LC-MS/MS on a Thermo Scientific Q Exactive+ Orbitrap Mass spectrometer coupled with a Proxeon Easy-nLC II HPLC (Thermo Scientific) Proxeonnanospray source. The peptides were separated using a $75 \mu \mathrm{m} \times 150 \mathrm{~mm}$

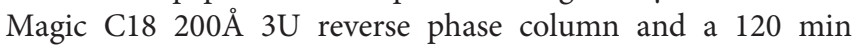
gradient with a flow rate of $300 \mathrm{~nL} / \mathrm{min}$. Data was acquired from $350-1600 \mathrm{~m} / z$ where the top ions were subjected to HCD (High Energy Collision Dissociation), and normalized collision energy of $27 \%$ was used for fragmentation. Tandem mass spectra were extracted by Proteome Discoverer version 1.2 charge state deconvolution and deisotoping were not performed. All MS/MS samples were analyzed using X! Tandem (The GMP group; https://www.thegpm.org/), which was set up to search the NCBI human refseq database and all-non-human common contaminants and an equal number of reverse sequences assuming the digestion of trypsin. Search allowed a fragment ion and a parent ion mass tolerance of 20 and $10 \mathrm{ppm}$, respectively. Scaffold v4.7.5 (Proteome Software Inc.; OR, USA) was used for data validation. Peptide identification was accepted if they achieved a threshold of 97\% using Sacaffold's LFDR algorithm, and protein identification was accepted if they contained at least two peptides at this threshold. Proteins sharing significant peptide evidence were grouped into clusters. Scaffold was also employed to identify the most abundant peptides of Transferon, which was based on the signal intensity (Total Ion Counts) and the probability of identification (>95\%).

\section{Intact Mass Analysis}

The intact mass of the Transferon peptides was determined by MS using the complete sequence of those proteins identified in the de novo sequencing. Eight Transferon batches (16E16, 16E15, $16 \mathrm{~F} 17,16 \mathrm{~F} 18,16 \mathrm{~J} 27,16 \mathrm{~J} 28,16 \mathrm{~J} 29,16 \mathrm{H} 15$, and $16 \mathrm{H} 26)$ were lyophilized and reconstituted in MS water (Honeywell; NJ, USA) at $2 \mathrm{mg} / \mathrm{mL}$. Additionally, a sample of batch $18 \mathrm{~A} 01$ was reduced and acetylated as previously described. A $10-\mu \mathrm{L}$ volume of Transferon samples and recombinant human $\mathrm{Ub}(1 \mu \mathrm{g} / \mathrm{mL}$; Boston Biochem Inc.; MA, USA) was injected on a Vion ${ }^{\circledR}$ ESIIMS-Q-ToF coupled to an Acquity ${ }^{\circledR}$ UPLC Class I system (Waters; MA, USA) and separated using a $1.7 \mu \mathrm{m}$ CSH C18 $(2.1 \mathrm{~mm} \times 150 \mathrm{~mm})$ column for identification and quantitation of Ub and a $3.0 \mu \mathrm{m} \mathrm{C18}(2.1 \times 150 \mathrm{~mm})$ BioSuite ${ }^{\circledR}$ column for verification of $\mathrm{Ub}$ identity (Both columns were purchased from Waters) at $60^{\circ} \mathrm{C}$. Samples were eluted at $0.2 \mathrm{~mL} / \mathrm{min}$ using water + formic acid ( $0.1 \%$ ) (phase A) and acetonitrile + formic acid $(0.1 \%)$ (phase B) as follows: $100 \%$ from 0 to 10 min of phase $\mathrm{A}$, and a gradient of 100 to $50 \%$ from 10 to $85 \mathrm{~min}$ of phase A. Mobile phase reagents were MS grade and were purchased from Honeywell and Thermo Scientific. IMS-QTof was operated in positive polarity and sensitivity $\mathrm{MS}^{\mathrm{E}} /$ mode from 50 to $2000 \mathrm{~m} / z$. Collision energies were $5.00 \mathrm{eV}$ (low), $10.00 \mathrm{eV}$, (high), and 35.00 $\mathrm{eV}$ (high collision energy ramp end). Electrospray Ionization (ESI) parameters were set at $150^{\circ} \mathrm{C}$ source temperature, $450^{\circ} \mathrm{C}$ desolvation temperature, $0 \mathrm{~L} / \mathrm{h}$ cone gas, $1,000 \mathrm{~L} / \mathrm{h}$ desolvation gas, and $2.75 \mathrm{kV}$ capillary voltage. A $50-\mathrm{pg} / \mu \mathrm{L}$ Leucine Enkephalin solution (Waters, $556.2766 \mathrm{~m} / z$ ) was infused during the MS analysis at $5 \mu \mathrm{L} / \mathrm{min}$ for mass correction. Data were acquired and processed using Vion ${ }^{\circledR}$ software in which complete sequence of those proteins identified in de novo sequencing was loaded, and all possible peptides derived from LysC/Trypsin in-specific digestion were searched with a $25 \mathrm{ppm}$ tolerance; none chemical or posttranslational modifications were considered.

\section{Detection of Ubiquitin by ELISA}

The presence of monomeric Ubiquitin (Ub) in Transferon was indirectly confirmed by indirect ELISA employing antiTransferon antibodies and the kit OptEIA ${ }^{\circledR}$ (BD Biosciences; CA, USA) according to the manufacturer's instructions. Maxisorp ELISA plates (Nunc; Roskilde, Dinamarca) were coated with $50 \mu \mathrm{L}$ of recombinant human Ub $(10 \mu \mathrm{g} / \mathrm{mL})$ in pH 9.5 carbonate buffer solution (BD Biosciences) at $4^{\circ} \mathrm{C}$ overnight. Ub detection was achieved using an in-house developed polyclonal anti-Transferon antibody (dilution 1:250) (Mellado-Sanchez et al., 2019) or a commercial polyclonal antiUb antibody (dilution 1:300; Boston Biochem Inc.), both developed in rabbit. Primary antibodies were detected using an anti-rabbit IgG antibody coupled to Horseradish Peroxidase (dilution 1:2,500; Sigma-Aldrich). Data were analyzed at 450 $\mathrm{nm} / 570 \mathrm{~nm}$ in an Epoch ${ }^{\circledR}$ spectrophotometer (BioTek ${ }^{\circledR}$; VT, USA) after performing the colorimetric reaction with a 3,3',5,5' Tetramethylbenzidine (TMB) (BD Biosciencs). Data were processed using the Gen5 software (BioTek $\left.{ }^{\circledR}\right)$. 


\section{Identification of Ub Using Anti-Ub Polyclonal Antibodies and MS}

The total Ub content of Transferon was removed using an antiUb polyclonal antibody (Boston Biochem Inc.) and used as a negative control in the in vivo assay. Transferon sample (batch 19J20) were lyophilized and reconstituted in water for injection (Pisa Laboratories) at $2 \mathrm{mg} / \mathrm{mL}$. A $200 \mu \mathrm{L}$ volume was incubated with $2 \mu \mathrm{L}$ of anti-Ub polyclonal antibody (Boston Biochem Inc.) at $4^{\circ} \mathrm{C}$ overnight. Then, the sample was filtrated by centrifugation through a $50 \mathrm{kDa}$ membrane (Millipore; MA, USA); the permeate and the retained fractions were analyzed by the MS intact method to confirm the removal of Ub. The permeate was sterilized by filtration using a $0.22 \mu \mathrm{m}$ membrane (Millipore) and stored at $4^{\circ} \mathrm{C}$ until use.

\section{Comparison of Ub and Ub(-GG) Structures by Homology Modeling}

$\mathrm{Ub}$ and $\mathrm{Ub}(-\mathrm{GG})$ were modeled to determine the effect of the lack of two-terminal Gly in their structure. A protein structure homology modeling was applied using SWISS-MODEL (Guex et al., 2009; Bertoni et al., 2017) based on the 2jwz.1.A structure, which was obtained by nuclear magnetic resonance (NMR) and shared a $94.74 \%$ of homology with Ub.

\section{Quantitation of Total Ub by MS}

The total concentration of $\mathrm{Ub}[\mathrm{Ub}+\mathrm{Ub}(-\mathrm{GG})]$ was calculated in eight Transferon batches (18A01, 18A02, 18A03, 18A04, 18B05, $18 \mathrm{E} 13,18 \mathrm{E} 14$, and 18E16) by MS. Transferon samples were lyophilized, reconstituted with $100 \mu \mathrm{L}$ of MS water (Honeywell) and added with $10 \mu \mathrm{L}$ of $32 \mathrm{pmol} / \mu \mathrm{L}$ Glu-1-fibrinopeptide B (Glufib) as an internal standard. Samples were analyzed using the intact mass MS method, as previously described. The deconvoluted area of $\mathrm{Ub}$ and $\mathrm{Ub}(-\mathrm{GG})$ was obtained, added and corrected vs. Glufib response. The total Ub concentration was calculated using a recombinant human Ub (Boston Biochem Inc.) standard curve also prepared with Glufib. Data were acquired and processed with the UNIFI ${ }^{\circledR}$ software.

\section{HSV-1 Infection Murine Model}

The relevance of the Ub content in Transferon was evaluated using an HSV-1 infection murine model, as previously described by Salinas-Jazmin and cols. (Salinas-Jazmin et al., 2015); trained researchers blindly performed all procedures. Briefly, 4-week-old and 14-18 g weigh male BALB/c mice (Ferandelh; Mexico City, Mexico) were shaved on the back and anaesthetized with $10 \mu \mathrm{L} / \mathrm{g}$ of $6.4 \mathrm{mg} / \mathrm{mL}$ sodium pentobarbital (Pisa Laboratories) via intraperitoneal. Mice had ad libitum access to standard chow (Harlan Labs; IN, USA) and filtered water. They were housed in a P/NC IVC system (Allentown Inc.; NJ, USA) at $22^{\circ} \mathrm{C} / 55 \%$ relative humidity and 12-h light/dark cycle. After $24 \mathrm{~h}$ of infection, Day 0 , mice were inoculated by cutaneous scarification with $10 \mu \mathrm{L}$ of $5 \times 10^{6} \mathrm{PFU} / \mathrm{mL}$ of Herpes simplex virus type 1 (HSV-1) Koss strain, previously expanded in African Green Monkey Kidney cells (Vero ${ }^{\circledR}$ CCL-81) and Eagle's minimal essential medium (EMEM) supplemented with $10 \%$ of fetal bovine serum, all acquired from ATCC (VA, USA). On day
2 , infected mice were grouped $(\mathrm{n}=9)$ and ORO administered with the next treatments: Transferon $(0.75 \mu \mathrm{g} / 200 \mu \mathrm{L})$, Transferon $(0.75 \mu \mathrm{g} / 200 \mu \mathrm{L})+\mathrm{Ub}(0.75 \mu \mathrm{g} / 200 \mu \mathrm{L})$, Ubdepleted Transferon $(\approx 0.75 \mu \mathrm{g} / 200 \mu \mathrm{L})$, and Ub $(0.75 \mu \mathrm{g} / 200$ $\mu \mathrm{L})$. Recombinant human Ub (Boston Biochem Inc.) was employed. Groups received the same treatment every other day until day 10 and were maintained under observation until day 20 along with a non-infected/non-treated control (negative control) and infected/non-treated (infection control). During the assay, mice were daily monitored to identify infection-associated symptoms, such as paralysis of the lower extremities, reduced mobility, and weight loss. Animals were euthanized if they experienced a total loss of mobility; these events were counted as deaths. All procedures were performed according to Mexican and International Guides for Care and Use of Laboratory Animals (Secretaría de Agricultura, 1999; Animals, 2011) and approved by the Ethical Committee of the Transfer Factor Project (protocol FTU/IB/012/010/PRO) (Salinas-Jazmin et al., 2015). All efforts were made to minimize animal suffering.

\section{Statistics}

The percentage contribution of proteins to the total mass spectrum of Transferon and their percentage of coverage are reported as the average value $(n=10)$. In both cases, the standard deviation (SD) bar is provided. The hit number per peptide is also reported as the average of the 10-batch analysis. In the ELISA assay, a D'Agostino-Pearson omnibus normality test was performed to determine normal distribution in the study groups, then a Kruskal-Wallis test followed by a Dunn's multiplecomparison test was applied to determine statistical difference among groups. The percentage of survival is presented using a Kaplan-Meier survival plot. All these statistical analyzes were performed using GraphPad Prism, version 6.00 for Windows (GraphPad Software, La Jolla CA, USA).

\section{RESULTS}

\section{MS Sequencing Analysis}

A two-stage mass spectrometric analysis was performed to determine the most abundant peptide component of Transferon. In the first stage, 10 batches of Transferon were de novo sequenced using a trypsinization method (Figure 1). In this analysis, it was found that each Transferon sample is made up of around 20,000 peptides derived from 593 human proteins. These results were analyzed to describe the peptide composition of Transferon qualitatively. In this sense, the protein clusters were ordered from highest to lowest spectrometric intensity, an selected those that i) appeared consistently among the 10 batches analyzed (reproducibility), ii) were identified with a probability higher than 95\%, and iii) whose spectrometric intensity was above the signal/noise ratio, which was defined as the point where sequences from keratin, a common environmental pollutant in this type of analysis, were detected (Hodge et al., 2013). It was determined that the most abundant Transferon peptides, based on the intensity of their mass 


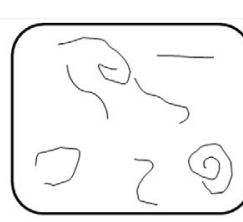

Transferon Oral

$(2 \mathrm{mg} / \mathrm{mL} ; \mathrm{n}=10)$

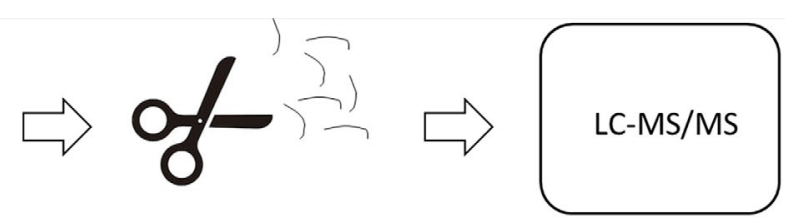

Sample treatment and digestión with Trypsin/Lys-C
Sequencing

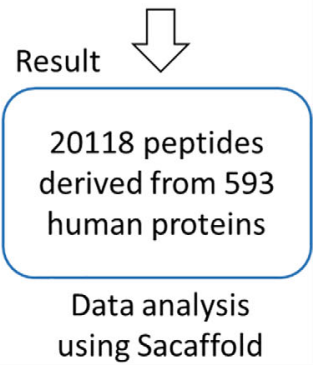

FIGURE 1 | Sequencing analysis of Transferon by MS. Transferon peptides were digested using Trypsin/Lys-C and sequenced by LC-MS/MS. The obtained peptide mass spectrum were prioritized based on its mass intensity, reproducibility among batches, signal and identification reliability. The batch-to-batch reproducible peptides of Transferon come from 22 proteins.

spectrum, come from 22 human proteins, 18 of them grouped in clusters (Table 1). Overall, these peptides account for the $4,319 \%$ (SD < 1.03) of the total peptide content of Transferon, being the ankyrin (ANK-1) peptides that contribute the most (Figure 2).

The contribution of each protein to the mass spectrum of Transferon depends on: i) the number of peptides provided to the mixture and ii) the spectral intensity of each peptide. Thus, the relative abundance per protein in Transferon was qualitatively calculated based on the percentage of coverage and the average hit number of their peptides. The coverage map of Transferon evinced that its batch-to-batch reproducible peptides come from different protein regions: C-Terminal end (ankyrin-1), N-Terminal end (actin, cytoplasmic 1), and, in some cases, from the whole protein (hemoglobin subunit $\beta$ and thymosin clusters) (Figure 3A). The percentage of coverage analysis revealed that ANK-1, a $206-\mathrm{kDa}$ protein, contributes with $14 \%$ of its sequence to Transferon, whereas low-molecular mass protein clusters provide with more than $60 \%$, i.e., hemoglobin subunit $\beta$ (16 kDa), $\alpha$-synuclein $(14 \mathrm{kDa})$, and polyubiquitin-C (17 kDa) (Figure 3B). Further, it was obtained the average number of hits per peptide as an indicator of relative abundance. At this regard, the peptides that appeared in at least eight out of 10 sequenced batches were selected. One hundred thirty-six relevant peptides were identified, and their average number of hits were grouped in a high ( $>80$ hits) or intermediate (40-80) hit region (Figure 4). It was found that the high contribution of ANK-1 to the mass spectrum of Transferon is because this cluster contributes the highest number of peptides, 17 in total. In counterpart, a peptide from the polyubiquitin-C (UBC) cluster had the maximum number of hits (125) although this cluster has a lower contribution to the Transferon spectrum.

\section{Identification of $\mathrm{Ub}$ and $\mathrm{Ub}(-\mathrm{GG})$ in Transferon}

The de novo sequencing of Transferon allowed to i) identify the proteins that mainly contribute to its peptide fraction, ii) and to qualitatively describe its peptide content. However, it is not useful to identify Transferon peptides with a relevant biological activity because their identification was biased by the trypsinization procedure used during sample processing. In the second stage of MS characterization, an analysis of the intact mass of Transferon was performed using the whole sequence of the cluster identified in phase 1 . In this analysis, the highest total ion counting (TIC) signal was observed around $57 \mathrm{~min}$ (Figure 5A) using a $1.7-\mu \mathrm{m}$ CSH C18 column. Using the MaxEnt1 algorithm the 57 min signal was combined, and the obtained $\mathrm{m} / \mathrm{z}$ and its deconvoluted mass (Figures 5B, C, respectively) were very similar to the theoretical mass of monomeric Ub (8564.84 Da). Interestingly, in the same chromatographic peak, a second peptide signal with a similar mass to monomeric Ub was observed $(8449.0 \mathrm{kDa})$. The presence of monomeric Ub in Transferon was verified by analyzing a recombinant human monomeric Ub standard and Transferon side-by-side using a 3.0- $\mu$ C18 BioSuite ${ }^{\circledR}$ column; both samples exhibited the same TIC profile at the elution time of monomeric Ub, i.e., from 50 to $69 \mathrm{~min}$ (Figure 6A). The combination of the TIC profile of Transferon from 50 to $69 \mathrm{~min}$ evinced two sets of signals, as previously observed using the small-size particle CSH C18 column, one of them was similar to the standard of monomeric Ub (Figure 6B). After deconvolution by a MaxEntl algorithm, these sets of $\mathrm{m} / \mathrm{z}$ signals of Transferon were assigned to the monomeric Ub $(8564.50 \mathrm{Da})$ according to the intact mass of the Ub standard, and the second set, the most intense, to an Ubrelated structure that lacks the two terminal glycine [Ub(-GG); 
TABLE 1 | Main proteins than provide of peptide components to Transferon.

\begin{tabular}{|c|c|c|c|c|c|}
\hline & Protein or cluster & Protein accession number & $\begin{array}{l}\text { Percentage of total } \\
\text { Transferon oral } \\
\text { spectrum (\%) }\end{array}$ & SD & Link to access the full sequence \\
\hline C1 & Cluster of Ankyrin-1 & $\begin{array}{l}\text { 1) ANK1_HUMAN } \\
\text { 2) Q6PK32_HUMAN (ANK1_Fragment) }\end{array}$ & 0.784 & 0.14 & $\begin{array}{l}\text { https://www.uniprot.org/uniprot/P16157 } \\
\text { https://www.uniprot.org/uniprot/Q6PK32 }\end{array}$ \\
\hline P2 & Protein 4.1 & 3) 41_HUMAN & 0.517 & 0.12 & https://www.uniprot.org/uniprot/P11171 \\
\hline C3 & Cluster of Haemoglobin subunit $\alpha$ & $\begin{array}{l}\text { 4) HBA_HUMAN } \\
\text { 5) G3V1N2_HUMAN (HBA_Fragment) }\end{array}$ & 0.461 & 0.11 & $\begin{array}{l}\text { https://www.uniprot.org/uniprot/P69905 } \\
\text { https://www.uniprot.org/uniprot/G3V1N2 }\end{array}$ \\
\hline C4 & Cluster of Haemoglobin subunit $\beta$ & $\begin{array}{l}\text { 6) HBB_HUMAN } \\
\text { 7) E9PEW8_HUMAN (HBB_Fragment) }\end{array}$ & 0.457 & 0.09 & $\begin{array}{l}\text { https://www.uniprot.org/uniprot/P68871 } \\
\text { https://www.uniprot.org/uniprot/E9PEW8 }\end{array}$ \\
\hline P5 & Complement 3 protein (C3) & 8) CO3_HUMAN & 0.443 & 0.14 & https://www.uniprot.org/uniprot/P01024 \\
\hline C6 & Cluster of Calpastatin & $\begin{array}{l}\text { 9) ICAL_HUMAN } \\
\text { 10) AOAOAOMR45_HUMAN (ICAL_Fragment } \\
\text { 11) D6RC54_HUMAN (ICAL_Fragment 2) }\end{array}$ & 0.419 & 0.10 & $\begin{array}{l}\text { https://www.uniprot.org/uniprot/P20810 } \\
\text { https://www.uniprot.org/uniprot/A0A0A0MR45 } \\
\text { https://www.uniprot.org/uniprot/D6RC54 }\end{array}$ \\
\hline C7 & Cluster of $\alpha$-synuclein & $\begin{array}{l}\text { 12) SYUA_HUMAN } \\
\text { 13) H6UYS7_HUMAN (SYUA_Fragment) }\end{array}$ & 0.248 & 0.05 & $\begin{array}{l}\text { https://www.uniprot.org/uniprot/P37840 } \\
\text { https://www.uniprot.org/uniprot/H6UYS7 }\end{array}$ \\
\hline P8 & Fibrinogen $\alpha$-chain & 14) FIBA_HUMAN & 0.231 & 0.08 & https://www.uniprot.org/uniprot/P02671 \\
\hline C9 & Cluster of Actin, cytoplasmic 1 & $\begin{array}{l}\text { 15) ACTB_HUMAN } \\
\text { 16) IIL3R2_HUMAN (ACTB_Fragment) } \\
\text { 17) POTEE_HUMAN }\end{array}$ & 0.223 & 0.06 & $\begin{array}{l}\text { https://www.uniprot.org/uniprot/P60709 } \\
\text { https://www.uniprot.org/uniprot/3L3R2 } \\
\text { https://www.uniprot.org/uniprot/Q6S8J3 }\end{array}$ \\
\hline C10 & $\begin{array}{l}\text { Cluster of Polyubiquitin-C } \\
\text { (monomer) }\end{array}$ & $\begin{array}{l}\text { 18) UBC_HUMAN } \\
\text { 19) J3QRK5_HUMAN (UBC_Fragment) }\end{array}$ & 0.218 & 0.05 & $\begin{array}{l}\text { https://www.uniprot.org/uniprot/POCG48 } \\
\text { https://www.uniprot.org/uniprot/J3QRK5 }\end{array}$ \\
\hline C11 & Cluster of Thymosin & $\begin{array}{l}\text { 20) TYB4_HUMAN } \\
\text { 21) TYB10_HUMAN }\end{array}$ & 0.160 & 0.04 & $\begin{array}{l}\text { https://www.uniprot.org/uniprot/P62328 } \\
\text { https://www.uniprot.org/uniprot/P63313 }\end{array}$ \\
\hline $\begin{array}{l}\text { P12 } \\
\text { Glob }\end{array}$ & $\begin{array}{l}\text { Zyxin } \\
\text { al values }\end{array}$ & 22) ZYX_HUMAN & $\begin{array}{l}0.158 \\
4.319\end{array}$ & $\begin{array}{l}0.05 \\
1.03\end{array}$ & https://www.uniprot.org/uniprot/Q15942 \\
\hline
\end{tabular}

These proteins were identified in the MS sequencing analysis using Trypsin/LysC digestion and are presented in decreasing order according to their total spectrometric intensity. The SD obtained in the 10-batch sequencing analysis is also provided. C, cluster; P, protein.

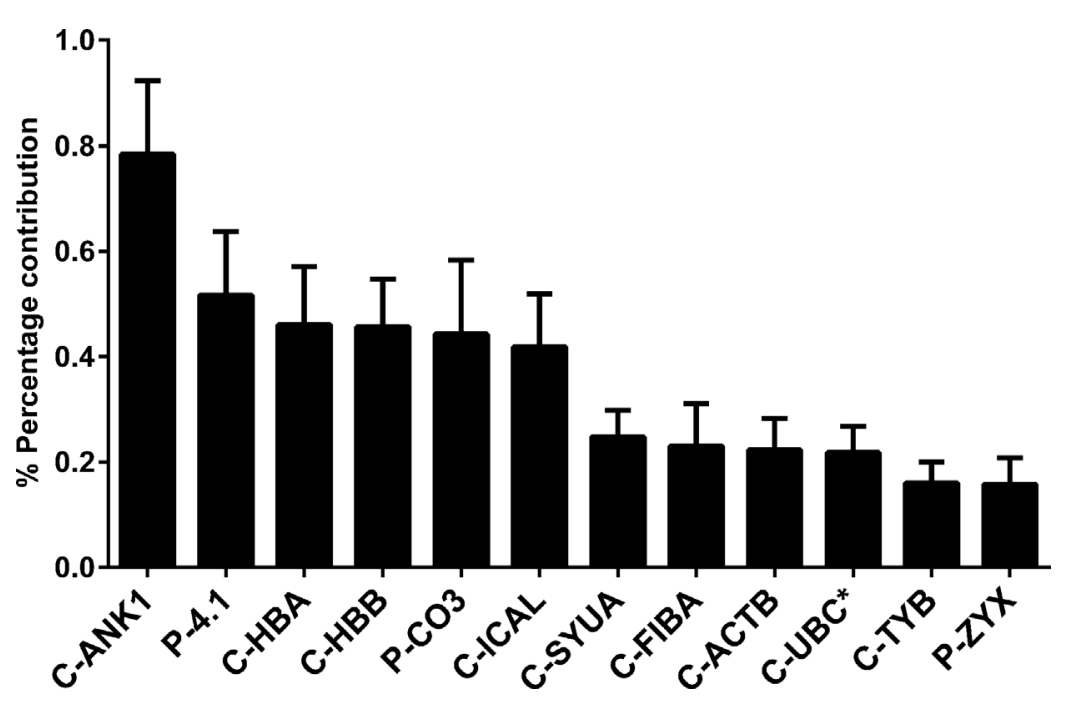

FIGURE 2 | Percentage of the contribution of proteins to the mass spectrum of Transferon. The relevance of proteins that consistently provide peptides to Transferon was determined based on their the average total mass spectrum obtained in the 10-batch sequencing analysis. The cluster ANK-1 contributes the most to the mass spectra of Transferon. The bars indicate standard deviation (SD) of the analysis. *, monomer. Clusters: ankyrin (ANK-1), hemoglobin subunit $\alpha$ (HBA), hemoglobin subunit $\beta(\mathrm{HBB})$, calpastatin (ICAL), $\alpha$-synuclein (SYUA), fibrinogen $\alpha$-chain (FIBA), cytoplasmic actin 1 (ACTB), polyubiquitin C (UBC), thymosin (TYB); Proteins: protein 4.1 (4.1), complement C3 protein (CO3), and zyxin (ZYX).

$8450.5 \mathrm{kDa}$ ] according to the predicted sequence by the UNIPROT software and to the theoretical mass calculation of $\mathrm{Ub}(-\mathrm{GG})$ using the ExPASy tool (8450.74 Da) (Figure 6C). A reduced sample of Transferon was analyzed under the same analytical conditions to confirm that the $\mathrm{m} / z$ signals attributable to $\mathrm{Ub}$ and $\mathrm{Ub}(-\mathrm{GG})$ instead of peptide aggregates. The reduced sample also showed the $\mathrm{Ub}$ and $\mathrm{Ub}$ (-GG) $m / z$ patterns (Figure S1). Further, the TIC and $m / z$ profiles of $\mathrm{Ub}$ and $\mathrm{Ub}(-\mathrm{GG})$ were reproducible in 8-batch Transferon MS analysis (Figure S2). 
A

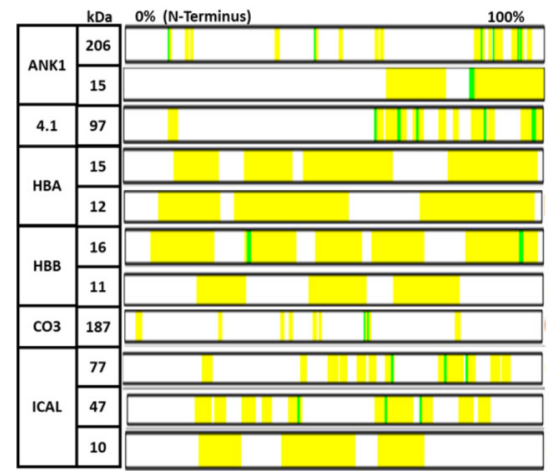

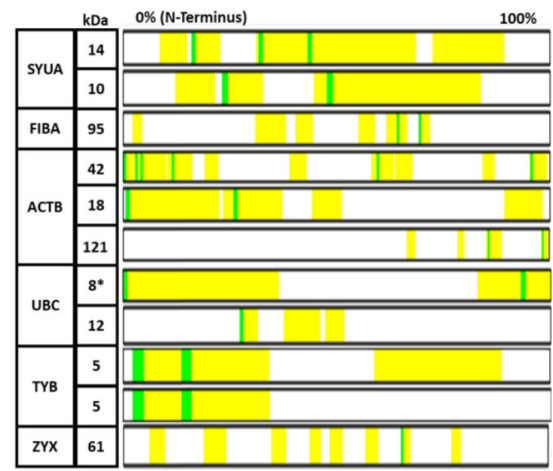

B

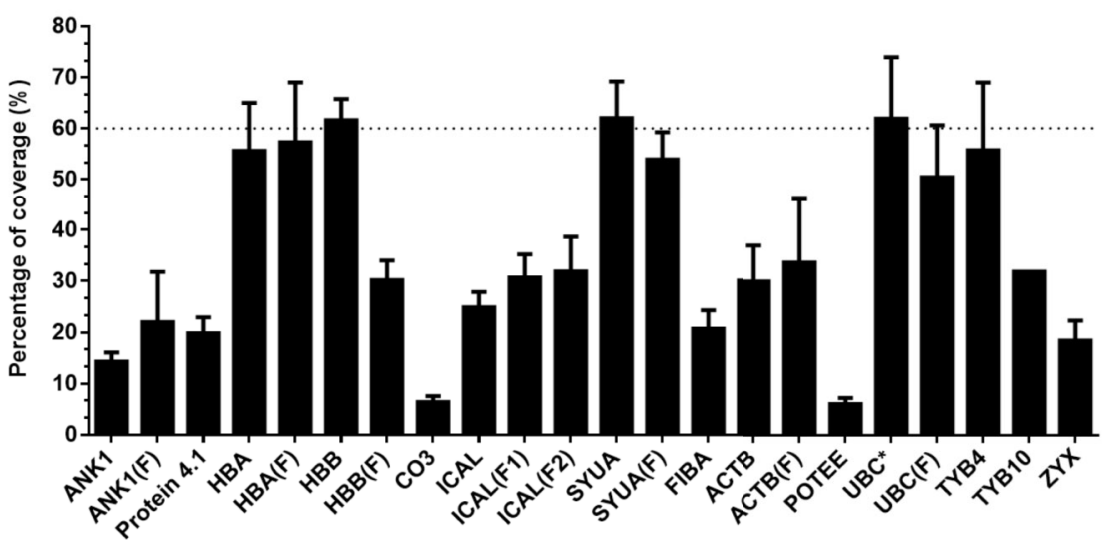

FIGURE 3 Analysis of the percent coverage of the proteins that consistently provide peptides to Transferon. The proteins that consistently provide peptides to Transferon were individually analyzed, and their total contribution was reported as the percent of coverage. (A) The map of the peptides found in the sequencing analysis of batch $14 \mathrm{G} 18$ is showed as an example; the identified peptides are marked in yellow and in green chemical modification. Note that the length of the proteins was normalized and does not represent its real size. (B) Average percentage coverage per protein obtained in the 10-batch sequencing analysis. The average percent of coverage of HBB, SYUA and monomer UBC was 61.6, 62.0, and 62.2\%, respectively. The bars indicate the SD of the 10-batch analysis. C-, cluster; (F), fragment; *, monomer; ankyrin (ANK-1), hemoglobin subunit $\alpha$ (HBA), hemoglobin subunit $\beta$ (HBB), complement C3 protein (CO3), calpastatin (ICAL), $\alpha$-synuclein (SYUA), fibrinogen $\alpha$-chain (FIBA), cytoplasmic actin 1 (ACTB), POTE ankyrin domain family member $E$ (POTEE), polyubiquitin C (UBC), thymosin $\beta 4$ (TYB4), thymosin $\beta 10$ (TYB10), and zyxin (ZYX).

The identity of $\mathrm{Ub}$ and $\mathrm{Ub}(-\mathrm{GG})$ in Transferon was also determined using polyclonal antibodies. A polyclonal antiTransferon antibody, which was generated by our group (Mellado-Sanchez et al., 2019), recognized recombinant human monomeric $\mathrm{Ub}$, as well as a commercial polyclonal anti-Ub antibody (Figure 7A). Besides, a sample of Transferon (2 mg/ $\mathrm{mL}$ ) was incubated with a commercial polyclonal anti-Ub antibody at $4^{\circ} \mathrm{C}$ overnight and filtered through a $100 \mathrm{kDa}$ membrane. The analysis of intact mass showed that the anti-Ub antibody retained both $\mathrm{Ub}$ and $\mathrm{Ub}$ (-GG) during filtration (Figure 7B). This result also confirmed that the two sets of $m / z$ signals that co-elute at $55 \mathrm{~min}$ in the TIC profile of Transferon correspond to $\mathrm{Ub}$ and $\mathrm{Ub}(-\mathrm{GG})$, two structurally and physicochemically similar peptide entities. The structural similarity between $\mathrm{Ub}$ and $\mathrm{Ub}$ (-GG) was also evaluated by homology-modeling using the SWISS-MODEL tool. The models obtained for Ub and Ub (-GG) and their Z-score values were similar ( 0.55 vs. 0.59$)$ (Figure 8A). Taking all these results into account, it was considered the $\mathrm{Ub}$ and the $\mathrm{Ub}(-\mathrm{GG})$ as the same entity (total Ub). In this sense, the total Ub was quantified in eight Transferon batches. A $5-\mathrm{mL}$ vial $(0.4 \mathrm{mg} / \mathrm{mL}$ of Transferon, equivalent to one dose) was lyophilized, reconstituted in water $(2 \mathrm{mg} / \mathrm{mL})$, and quantified by MS using a standard human monomeric Ub curve; the results were calculated in $\mu \mathrm{g} / \mathrm{dose}$, which is equivalent to $\mu \mathrm{g} / 5$ $\mathrm{mL}$. Quantification showed that the average content of the Ub (-GG) peptide almost doubles that of monomeric Ub $(0.637 \mu \mathrm{g} /$ dose vs. $0.366 \mu \mathrm{g} / \mathrm{dose})$ in Transferon and that the average content of total $\mathrm{Ub}$ is $1,003 \mu \mathrm{g} /$ dose (Figure $\mathbf{8 B}$ ).

\section{Evaluation of the Functional Relevance of $\mathrm{Ub}$ as the Main Peptide Component of Transferon}

A murine model of HSV-1 infection was used to assess the biological relevance of Ub in Transferon. In this model, BALB/c mice are infected with HSV-1, pharmacological treatment is ORO administered at 2, 4, 6, 8, and 10 days post-infection, and remain under observation for an additional 10 days to assess survival percentage. The administered treatments were Transferon $(0.50 \mu \mathrm{g} / 200 \mu \mathrm{L})$; Transferon added with monomeric Ub $(0.50$ 


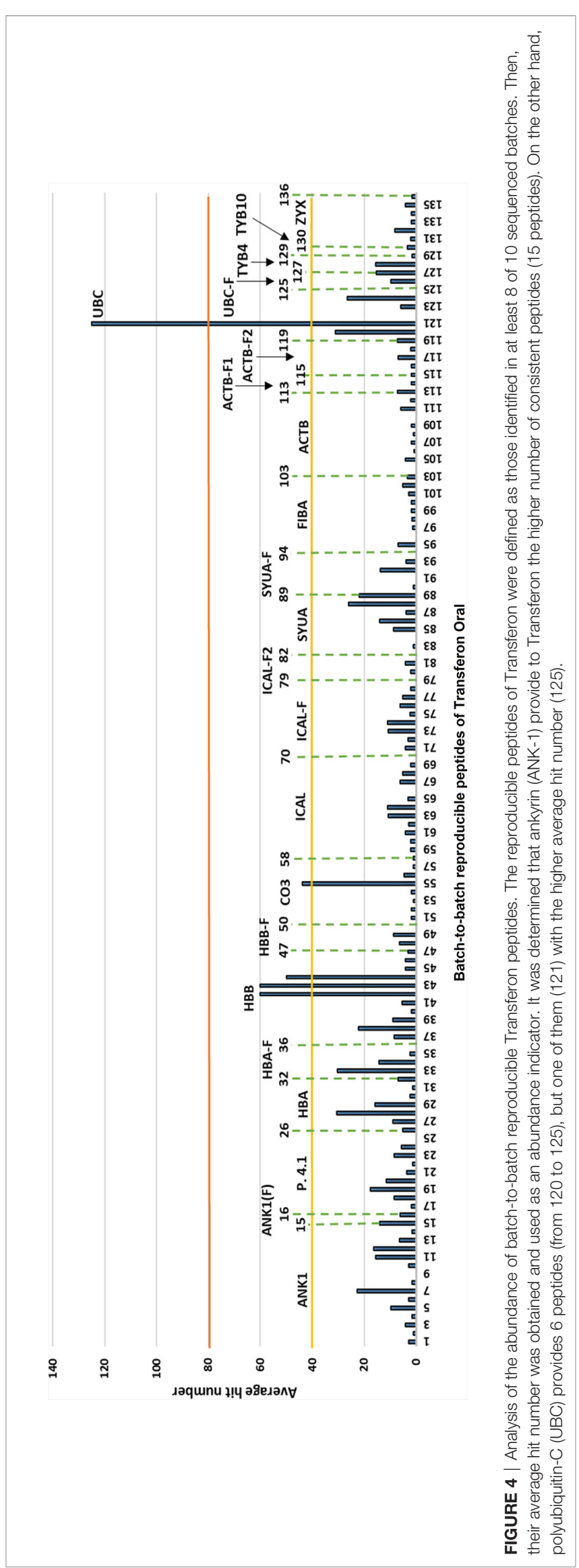

$\mu \mathrm{g} / 200 \mu \mathrm{L}+0.75 \mu \mathrm{g} / 200 \mu \mathrm{L}$, respectively); Ub-depleted Transferon $(\approx 0.50 \mu \mathrm{g} / 200 \mu \mathrm{L})$, which was removed with a commercial polyclonal anti-Ub antibody (Figure 7B); and Ub $(0.75 \mu \mathrm{g} / 200 \mu \mathrm{L})$ (Figure 9). In this assay, it was observed that the group treated with Transferon + Ub showed an increase in the percentage of survival compared to the group treated with Transferon only (77.7 vs. $66.6 \%$ ), whereas the percentage of survival decreased in the group treated with Ub-depleted Transferon compared to Transferon group (55.5 vs. 66.6\%). Interestingly, the group treated with Ub alone showed 100\% survival, as did the negative control group (no infection/no treatment). The concentration of Ub used for this assay was determined in a previous assay where it was observed that concentrations equivalent to less than $50 \%$ of Transferon did not induce significant changes in survival compared to the infection control (data not shown). Altogether, these results indicate that monomeric $\mathrm{Ub}$ is a major active component of the peptide mixture of Transferon.

\section{DISCUSSION}

Transferon is an extract obtained by the dialysis/filtration of human buffy coats, and its API is a complex mixture of peptides of less than $10 \mathrm{kDa}$ in size with a reproducible composition between batches (Medina-Rivero et al., 2016). This blood-derived product, which is marketed as an oral product (Transferon Oral) or as an injectable formulation (Transferon ${ }^{\circledR}$ ) when added with glycine and sucrose, is used in the treatment of diseases with an inflammatory component (Estrada-Parra et al., 1998; MedinaRivero et al., 2014). Preclinical and clinical information indicates that Transferon modulates the production of pro-inflammatory cytokines and improves the resolution of infectious diseases. However, the molecular bases of the therapeutic effects have not been fully understood, since it is not clear how the same product can induce Th1 or Th2 mechanisms depending on the condition in which it is used (Jimenez-Uribe et al., 2019). The immune "buffering" effect of dialyzable leukocyte extracts relay on their composition: there are regulatory molecules that control hypersensitivity and allergies, and an inducing fraction that reinforce the antigenic stimulus (Tulina et al., 2019).

Transferon is a complex biological drug composed of multiple peptide components. It is important to note that the mechanism of action of a complex drug is almost impossible to determine because it is the sum of the biological effects and signaling pathways activated by the multiple components of the drug during its residence time in the body. Notwithstanding, identifying the most abundant peptide component of Transferon, and the signaling pathways associated with it, will provide valuable information for better rational use and to develop new drugs with improved characteristics.

In this work, monomeric Ub was identified as the most abundant peptide component of the peptide mixture of Transferon based on its relative ionization intensity in a set of UPLC-MS analysis. In addition, we evinced that monomeric Ub emulated the protective effect of the whole peptide mixture in an HSV-1 murine infection 

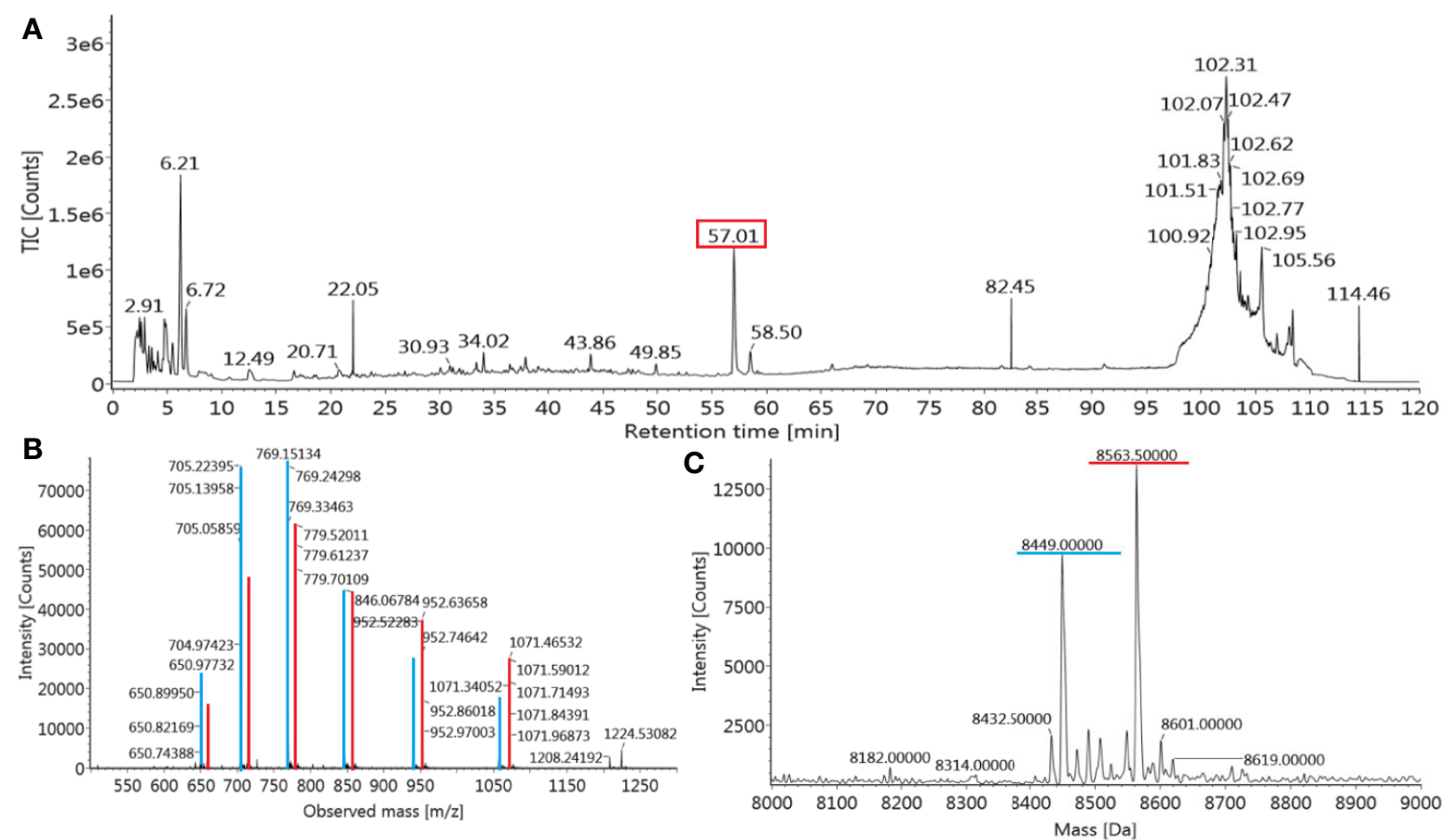

FIGURE 5 | Identification of monomeric Ub in Transferon. (A) Transferon (Batch 18A01; $2 \mathrm{mg} / \mathrm{mL}$ ) was analyzed by ESI-IMS-Q-ToF using an intact mass approach with a small-particle size column (CSH C18, $1.7 \mu \mathrm{m}$ ). The most intense $\mathrm{m} / \mathrm{z}$ signal of the total ion counting (TIC) profile was observed at $57.01 \mathrm{~min}$ (red square). (B) The $\mathrm{m} / \mathrm{z}$ profile and (C) the deconvoluted mass of the main Transferon TIC signal (marked in red) was similar to the theoretical values of monomeric Ub. A second peptide entity with a mass close to monomeric Ub (8449.0 Da) was also observed in the main chromatographic peak $(\mathrm{m} / z$ transitions in blue).

model when ORO administered. Taking into account that Transferon is a complex biological drug, all analyses were performed using 10 batches for reproducibility purposes.

\section{Sequencing Analysis of the Peptide Components of Transferon}

To the best of the authors' knowledge, there is only one report on the identification of peptide sequences in dialyzable extracts derived from mammalian cells (mice and bovine) in 2000 (Kirkpatrick, 2000). In this work, Kirkpatrick obtained the sequence of conserved peptides by Edman's degradation sequencing. However, those peptide sequences have not been found in any known proteome to date. Although Edman degradation is still the only actual sequencing technique today, its effectiveness is limited to high purity peptide samples (Fricker, 2015). Thus, this technique is not suitable for the analysis of DLE because these products are composed of a myriad of peptides with a low relative concentration. Nowadays, identification and quantitation of a vast number of peptides in complex samples are performed by different high-throughput methods, all based on MS (Schrader, 2018; Azkargorta et al., 2020; Pourjoula et al., 2020). In this sense, we proposed the use of high-resolution MS techniques coupled to high-performance liquid chromatography (UPLC) for the identification of the most abundant peptide component of Transferon. Considering that MS deduces the sequence of peptides based on spectral interpretation, we took into account the peptides identified with a high probability $(>95 \%)$ and narrowed the analysis to human peptides.

The identification of the peptide components of Transferon was performed in two stages: a de novo sequencing and an intact mass sequencing. In the first stage, the 12 protein clusters from which the reproducible peptides between batches $(4,319 \%$ of the total mass spectrum) were identified, being the ANK-1 cluster the most relevant. These protein clusters come from human leukocytes and erythrocytes. They can be grouped into: i) structural membrane proteins (Ankyrin, protein 4.1, Zyxin and $\alpha$-synuclein) and intracellular structural proteins (Actin-1 and thymosin $\beta 4$ ), ii) functional intracellular proteins (hemoglobin $\alpha$ and $\beta$ subunit, polyubiquitin $C$, and calpastatin) and plasma soluble proteins (fibrinogen $\alpha$ chain and complement C3 protein). Among them, some proteins directly affect the immune system: C3 protein plays a central role in the complement system cascade, a mechanism of the innate immune system (Vignesh et al., 2017); peptides derived from the $\alpha$-chain of fibrinogen elicit a lymphocyte suppressive functions (Plow and Edgington, 1986); extracellular hemoglobin ( $\alpha$ and $\beta$ chains) act as pathogen-associated molecular patterns (PAMP) and activates Toll-like receptors and, when oxidized, functions as a damage-associated molecular patterns (DAMP) (Lee and Ding, 2013); extracellular Ubiquitin has pleiotropic effects in inducing cytokine secretion 

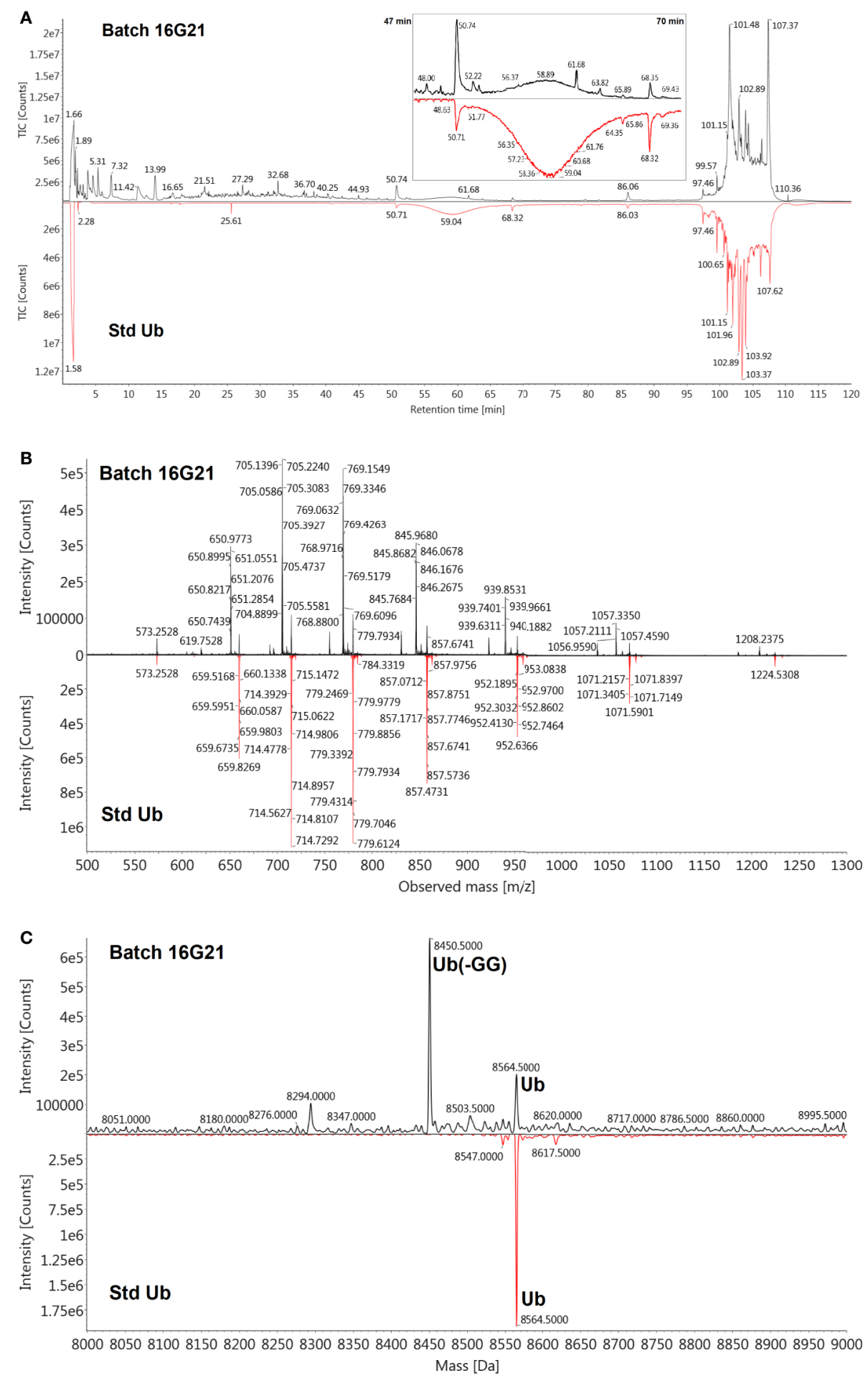

FIGURE 6 | Verification of the presence of Ub in Transferon and identification of Ub (-GG). (A) A monomeric standard of Ub (Std Ub) was analyzed by MS using a 3.0 m BioSuite ${ }^{\circledR}$ C18 column, along with the Transferon batch 16G21; both TIC profiles were similar from 47 to 70 min. (B) This segment of the TIC profile was combined and the $\mathrm{m} / \mathrm{z}$ signals between Transferon and SD Ub were also similar when compared in a mirror projection. (C) The deconvolution of the $\mathrm{m} / \mathrm{z}$ profiles of Transferon exhibited two masses, the firs (8564.5 Da) corresponded to that of the Std Ub (8564.5 Da), whereas the second $(8450.5 \mathrm{Da})$ to the theoretical mass value of monomeric $\mathrm{Ub}$ and monomeric $\mathrm{Ub}$ without two-terminal Gly [Ub(-GG); 8,450.74 Da]. 
A

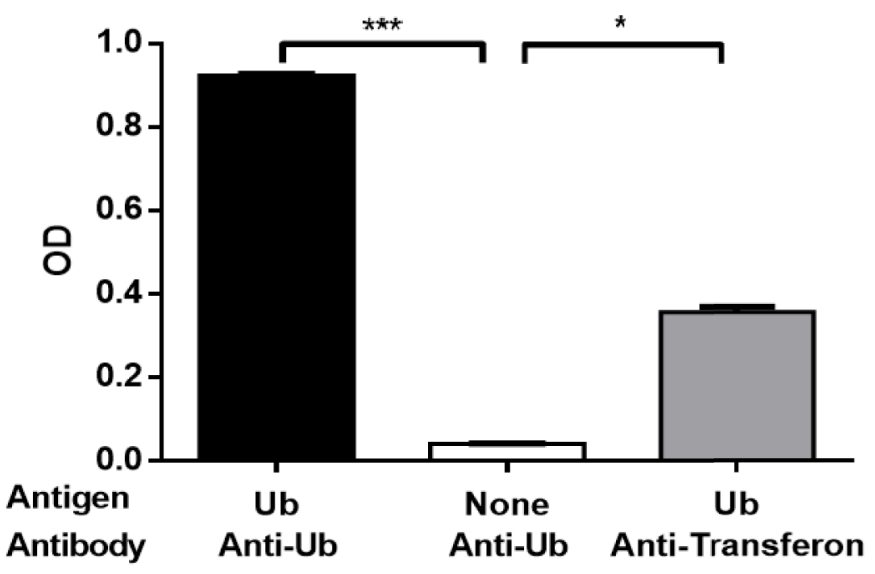

B Transferon
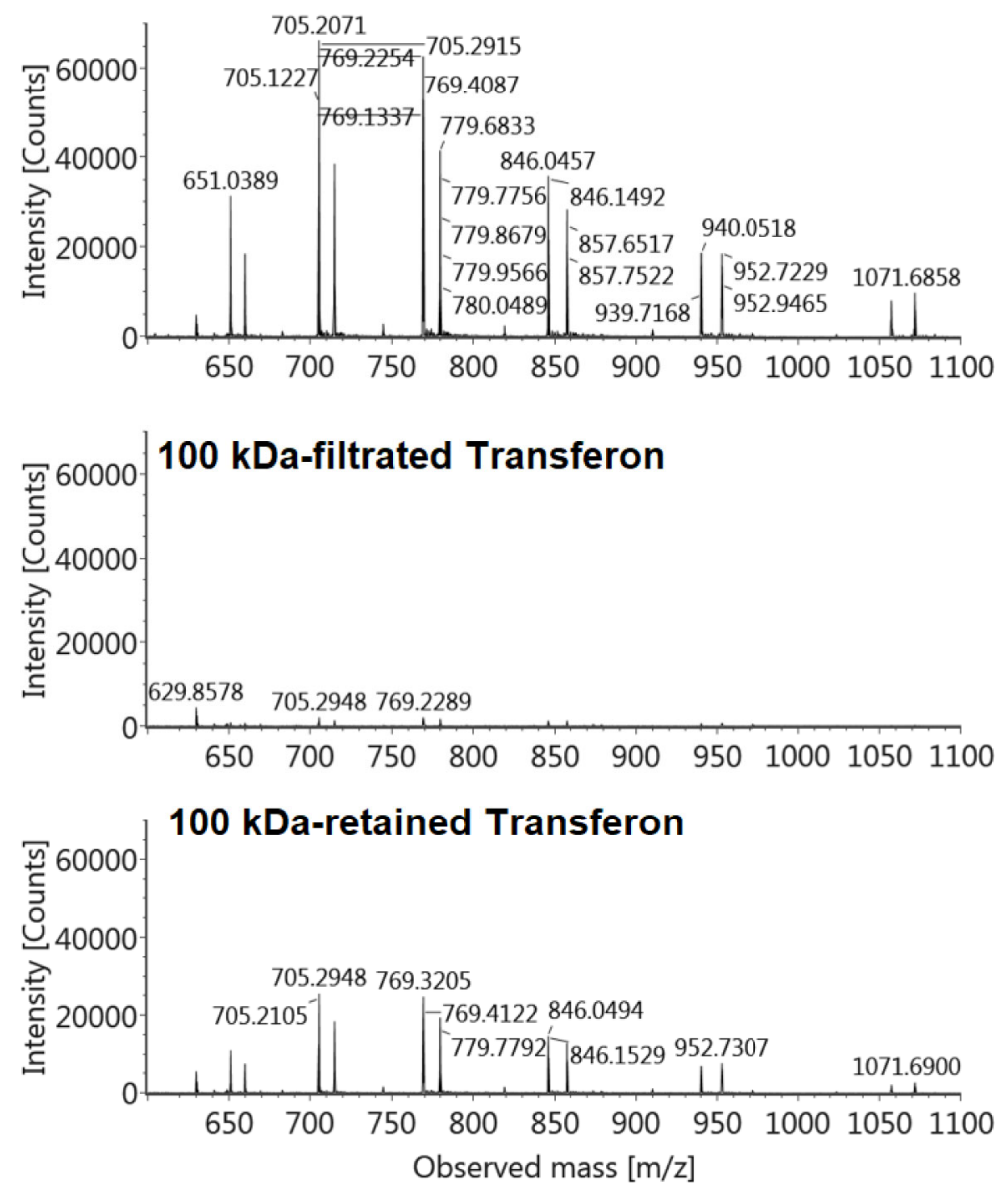

FIGURE 7 | Analysis of Ub and Ub(-GG) using polyclonal antibodies. (A) The presence of Ub in Transferon was indirectly confirmed using an anti-Transferon polyclonal antibody developed in rabbit by in-house methods (Mellado-Sanchez et al., 2019), which turned out to recognize monomeric Ub. The SD is presented per group. (B) Also, a $2 \mathrm{mg} / \mathrm{mL}$ of Transferon sample (Batch 19J20) was overnight incubated with a commercial anti-Ub polyclonal antibody (1:100 dilution) and filtrated through $100 \mathrm{kDa}$ membrane. Filtrated and retained fractions were analyzed by MS. SD bars are indicated per group. OD, optical density; TMB,

Tetramethylbenzidine; C, control. $\mathrm{H}=15.6 ;(\mathrm{d} f=2, \mathrm{~N}=18) ;{ }^{* \star \star} \mathrm{P}<0.001 ;{ }^{*} \mathrm{P}<0.05$. 
A

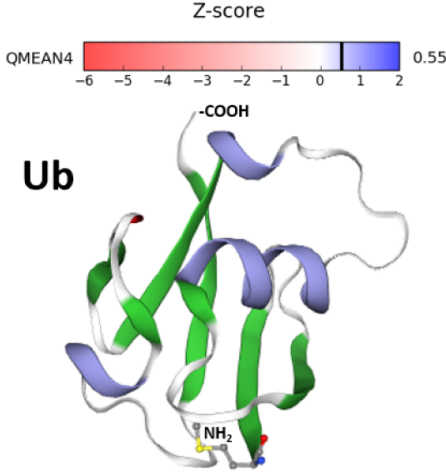

B

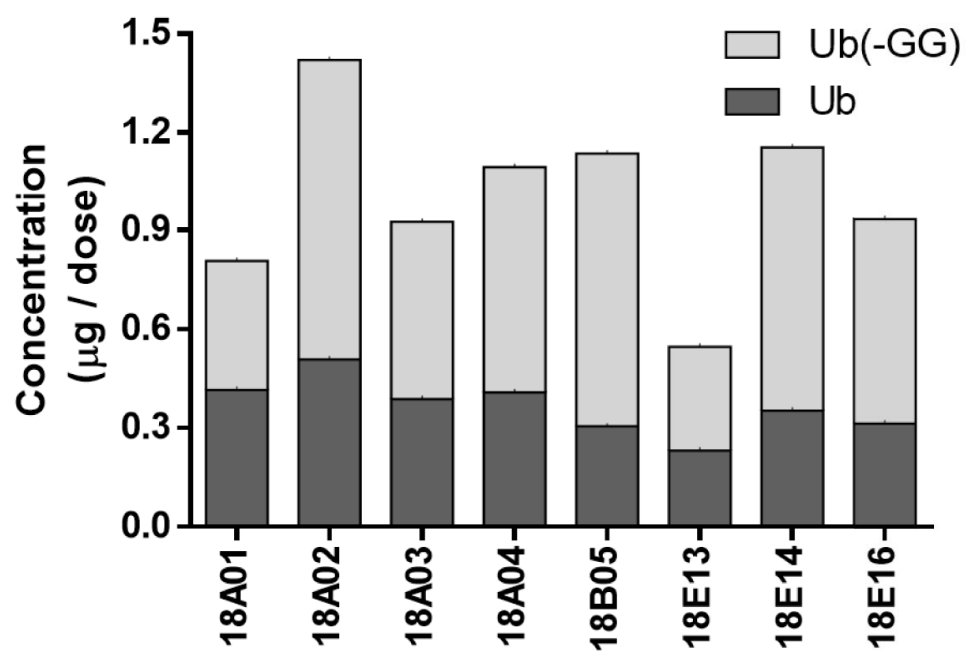

FIGURE 8 | Structural comparison of $\mathrm{Ub}$ and $\mathrm{Ub}(-\mathrm{GG})$ and total $\mathrm{Ub}$ quantitation in Transferon. (A) It was evaluated the impact of the lack of the terminal Gly on the structure of Ub using the SWISS-MODEL homology-modeling tool. Ub and Ub(-GG) were considered the same as they have similar shapes and Z-scores. (B) In this sense, the total $\mathrm{Ub}$ content of eight Transferon batches was quantitated per dose $(5 \mathrm{~mL})$ using the intact mass method. The average concentrations were $0.366 \mu \mathrm{g} /$ dose (CV, 22.97\%), $0.637 \mu \mathrm{g} / \mathrm{dose}$ (CV, 33.46\%), and $1.003 \mu \mathrm{g} /$ dose for monomeric Ub, Ub(-GG) and total Ub, respectively.

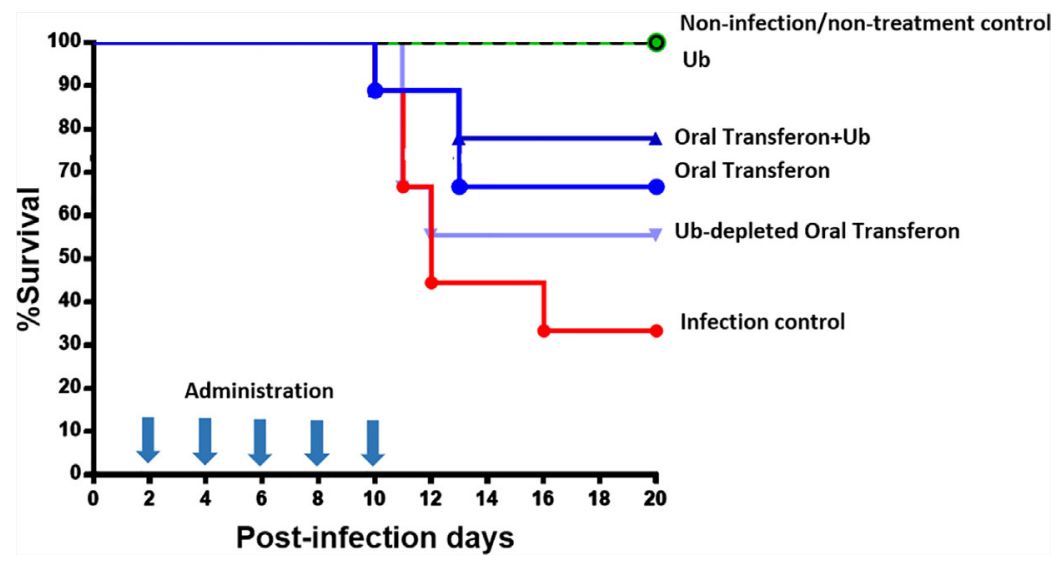

FIGURE 9 | Effect of Transferon and Ub in the HSV-1 infection murine model. HSV-1 infected mice were treated with Transferon (0.50 $\mu \mathrm{g} / 200 \mu \mathrm{L})$, monomeric Ub $(0.75 \mu \mathrm{g} / 200 \mu \mathrm{L})$, "Transferon Oral" + monomeric Ub, or monomeric Ub-depleted Transferon $(\approx 0.50 \mu \mathrm{g} / 200 \mu \mathrm{L})$. The addition of Ub to Transferon increased $(77.7$ vs. $66.6 \%$ ), and the removal of Ub decreased (55.5 vs. 66.6\%) the \%survival respect to the group treated only with Transferon. Ub treated group showed $100 \%$ of survival. 
and counteracts the inflammatory effect of DAMP (Patel et al., 2006; Majetschak, 2011), whereas thymosin $\beta 4$ regulates the inflammatory response derived from damage (Qiu et al., 2011). The nature of protein clusters that provide the most abundant peptides suggests that the main mechanisms of Transferon are related to the induction and regulation of DAMP signaling pathways and the innate immune system. However, extensive research is required to determine whether the peptides identified in Transferon retain the biological functions of the complete proteins from which they are derived.

Sequence coverage analysis showed that protein clusters provide peptides from different regions of their structure, in some from their C-terminal, N-terminal or along the entire protein sequence. This suggests that in the cell lysis stage by freeze/thaw cycles, during the manufacturing process of Transferon, proteases from leukocytes are released into the medium and digest the exposed cellular components in a random but controlled pattern. This process resembles the stage of polymerization and acid digestion of glatiramer acetate peptides, where up to $10^{36}$ peptides of an unknown sequence are generated, but with a consistent peptide polydispersion among batches (Campos-Garcia et al., 2017).

After analyzing the clusters and the proteins from which Transferon is generated, the peptides were individually evaluated. In this analysis, 136 reproducible peptides were identified among batches, and their relevance (abundance) was determined based on their average number of hits obtained in de novo sequencing of Transferon batches. It was determined that the spectral abundance of ANK-1 is because this cluster contributes with the highest variety of peptides (17 different peptides) to Transferon compared to the rest of the clusters. In contrast, the clusters of polyubiquitn- $\mathrm{C}$, hemoglobin $\beta$ subunit and protein $\mathrm{C} 3$ provide fewer peptide sequences but with a higher frequency (number of hits) per batch. Additionally, the high coverage percentage of low-molecular mass proteins $(<15 \mathrm{kDa})$, such as polyubiquitin $C$ (monomer), hemoglobin $\beta$ subunit, and $\alpha$ synuclein suggested that they could be complete in Transferon.

The disadvantage of de novo sequencing is that the sequence obtained from the peptides is biased by trypsin digestion during sample preparation. For this reason, the second stage of spectrometric analysis consisted of identifying the intact peptides. In this analysis, it was observed that the most intense signal of Transferon is due to two interrelated low-molecular mass proteins: the $\mathrm{Ub}$ monomer $(8.56 \mathrm{kDa})$ and a $\mathrm{Ub}$ variant that lacks its two terminal Gly [Ub(-GG); $8.45 \mathrm{kDa}$ ]. This observation correlated with the analysis of the number of hits where it was determined that the most frequent peptide come from the polyubiquitin- $\mathrm{C}$ cluster, and with the coverage map that suggested that the Ub monomer could be complete in Transferon. Remarkably, the analysis of intact mass showed that the monomeric $\mathrm{Ub}$ and its variant $\mathrm{Ub}(-\mathrm{GG})$ are the only complete proteins in Transferon, which indicates these structures resist enzymatic hydrolysis from its release, mainly from erythrocytes, to the finished product (Patel et al., 2006). This finding is based on the fact that the monomeric $\mathrm{Ub}$ is a natural serum globular protein of small size (76-amino-acid) that lacks posttranslational modifications and possesses high thermal, structural, and proteolytic stability (Job et al., 2015).

It is important to note that the identity of Ub was verified using and Ub standard by UPLC-MS in a straightforward way. On the other hand, the Ub(-GG) identity is assigned to the 8450.5-Da mass because of its high similarity to its theoretical mass $(8450.74 \mathrm{Da})$, and indirectly by comparing its physicochemical behavior to that elicited by Ub: i) both $\mathrm{m} / \mathrm{z}$ signals are recognized by commercial anti-Ub antibodies, which indicates similar sequences; ii) their $\mathrm{m} / \mathrm{z}$ patterns are similar, which evinces a similar content of ionizable groups; and iii) both structures co-elute in the UPLC-MS analysis, which indicates that have similar hydrophobic properties. This evidence highly suggests that the mass $8450.5 \mathrm{Da}$ corresponds to $\mathrm{Ub}(-\mathrm{GG})$. Notwithstanding, amino acid substitution in the primary sequence cannot be discarded in this work. In this sense, we will corroborate the full sequence of $\mathrm{Ub}(-\mathrm{GG})$ in further research.

\section{$\mathrm{Ub}$ as a Probe to Infer One Mechanism of Action of Transferon}

We evaluated the biological relevance of $\mathrm{Ub}$ and $\mathrm{Ub}(-\mathrm{GG})$ for Transferon using an HSV-1 infection murine model. For this purpose, we considered $\mathrm{Ub}$ and $\mathrm{Ub}(-\mathrm{GG})$ the same molecule (total $\mathrm{Ub}$ ) considering that are physicochemical and structurally similar and that the lack of terminal Gly does not affect the biological activity of extracellular Ub (Sloper-Mould et al., 2001). In HSV-I infection model, $\mathrm{Ub}(0.087 \mathrm{nM})$ and peptides $<10 \mathrm{kDa}$ were capable of inducing a protective effect. Remarkably, when the concentration of Ubiquitin in Transferon was modified using commercial antibodies against Ub or by adding recombinant monomeric human $\mathrm{Ub}$, the protective capacity of Transferon was diminished or augmented, respectively, which indicates that $\mathrm{Ub}$ is one of the active components of Transferon. Notwithstanding, considering that recombinant Ub elicited a protective effect at higher concentrations than the total $\mathrm{Ub}$ content of a standard batch of Transferon, there may be another peptide component that evoke a protective effect in the same model, and synergistic effects between them cannot be discarded.

$\mathrm{Ub}$ is a high-stable low-molecular mass protein detected in the serum of healthy humans in a concentration of less than 100 $\mathrm{ng} / \mathrm{ml}(<10 \mathrm{nM})$, and its main source are red cells (Takada et al., 1997; Patel et al., 2006). The intracellular function of Ub is wellknown. Nevertheless, the exact role of extracellular Ubiquitin is still under debate, although multiple experimental reports show that $\mathrm{Ub}$ or fragments of this protein attenuate pro-inflammatory responses (Jaremko et al., 2009; Majetschak, 2011). In our murine model of HSV-1 infection, a known concentration of Ub $(0.087 \mathrm{nM})$ and DAMPs-like peptides $(\sim 0.4 \mathrm{mg} / \mathrm{mL})$ is oropharyngeal deposited on five occasions during the clinical follow-up and improve the percent of survival of infected mice.

An elegant model of ischemia-reperfusion injury in C57BL/6 mice, infused monomeric $\mathrm{Ub}(1 \mathrm{mg} / \mathrm{g}$ per hour) and showed that Ub plays a protective role in myocardial remodeling post-I/R. In this model, Ub affects the cardiac function, the size area at risk/ infarct, levels of serum cytokines/chemokines, and demonstrates 
anti-inflammatory effects, through the receptors in the vagus nerve (Scofield et al., 2019). In this way, our group previously had reported that HSV-1 infected animals treated with Transferon, at equivalent doses to that used in humans, decrease TNF- $\alpha$ and IL- 6 and increase IFN- $\gamma$ serum levels, suggesting the presence of the same anti-inflammatory phenomenon (Salinas-Jazmin et al., 2015).
Considering the low concentration of the components of Transferon and the route of administration, we may hypothesize that total monomeric $\mathrm{Ub}(0.087 \mathrm{nM})$ and peptides $<10 \mathrm{kDa}$ interact directly with their receptors located in the stomach, such as TLR and the CXC motif chemokine receptor 4 (CXCR4) which has been recently suggested as a putative receptor for Ub with an affinity in the medium nM range (Saini et al., 2011). CXCR4 is
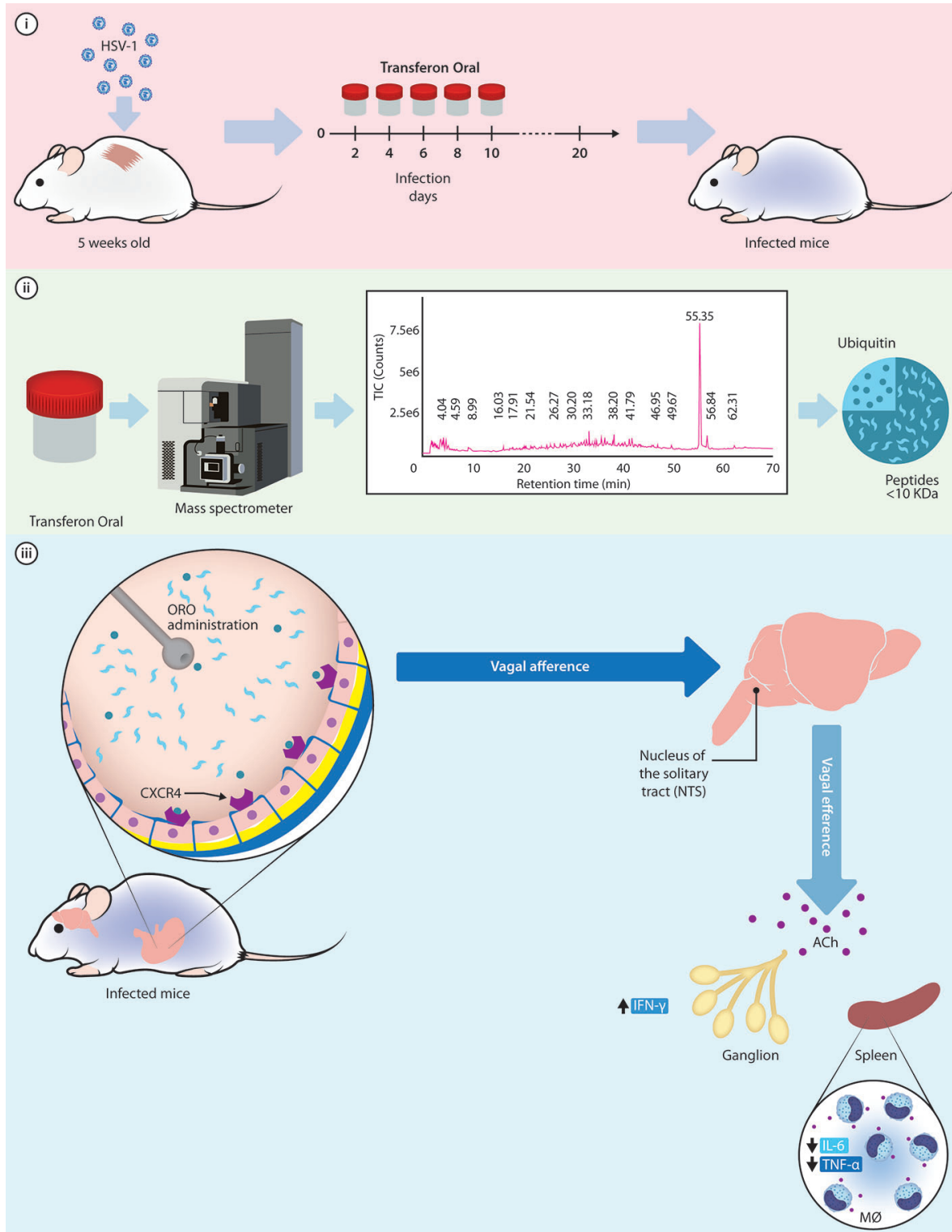

FIGURE 10 | Hypothetical mechanism of action of monomeric Ub to exert its protective function in the murine model of HSV-1 infection. i) Murine model of cutaneous HSV-1 infection can be used to examine the activity of Transferon, where mice receive five doses of the treatment after infection; ii) Through a mass spectrometry analysis, the monomeric Ub and its variant Ub(-GG) were identified as the most abundant peptide component of Transferon, with a total Ub concentration of $1.003 \mu \mathrm{g} / \mathrm{dose}$. iii) Once Ub, along with the rest of the peptides of Transferon, is ORO administered in the mice, it could activate the CXCR4 receptor on intragastric vagal nerve endings inducing an increase in ACh release at secondary lymphoid organs and spleen. Then, ACh attenuates the synthesis of TNF- $\alpha$ and IL-6, decreasing the inflammatory response in HSV-1infected mice infected and increasing the percentage of survival. HSV, Herpes simplex virus; ORO, oropharyngeal; ACh, acetylcholine; IL, interleukin; IFN, interferon; MØ, macrophages. 
expressed in the afferent endings of the vagus nerve at the stomach (Hermann et al., 2008) and its activation may lead to the inhibition of the release of TNF- $\alpha$ by spleen macrophages through acetylcholine (ACh) signaling pathways, as proposed by Figure 10 (Pavlov and Tracey, 2012; Bonaz et al., 2016; Browning et al., 2017; Pavlov and Tracey, 2017; Breit et al., 2018).

Our results suggest that the administration of a low concentration of a mix of monomeric $\mathrm{Ub}$ and peptides in $<10$ $\mathrm{kDa}$ in the stomach of animals infected with HSV-1 might activate sensory fibers that ascend in the vagus nerve to synapse in the nucleus tractus solitarius. Increased efferent signals in the vagus nerve suppress peripheral cytokine release through macrophage nicotinic receptors and the cholinergic anti-inflammatory pathway (CAIP). So that functions of extracellular Ubiquitin could constitute an evolutionarily conserved control mechanism aimed to balance the immune response and prevent exuberant inflammation induced by DAMP (Majetschak, 2011). Besides, Ub is a highly conserved across the mammalian class with extracellular anti-inflammatory effects on the innate system (Job et al., 2015), which may explain the inter-species effect of Transferon, e.g. mice (Salinas-Jazmin et al., 2015; Hernandez-Esquivel et al., 2018).

This is the first report that identify and characterize a peptide component of Transferon Oral, an hDLE extract, but further work is needed to ascertain the relevance of Ub in the HSV-1 infection murine model, its mechanism of action and its relevance among the Transferon peptide components. To challenge our hypothesis, we will perform further assays such as the determination of immunological parameters in the different treatments evaluated, such as cytokine levels and variations in lymphocyte subpopulations. We will carry out these analyzes in future work, along with the quantitation of Ub in Transferon using orthogonal analysis.

\section{CONCLUSION}

The sequencing analysis by MS concluded that the main peptides of Transferon come from 22 structural proteins. One of them, the monomeric $\mathrm{Ub}$, is complete or without the two-terminal Gly. The rest of the components are low-molecular mass peptides (less than $<10 \mathrm{kDa}$ ) and are reproducible between batches. It was observed that human monomeric Ub has a protective effect and that the protective effect of Transferon correlates with the monomeric Ub content in an HSV-1 murine infection model. Taking into account these results and the reported properties of monomeric Ub, we hypothesize that Transferon down-regulate the systemic inflammatory phenomenon induced by the infection through intragastric CXCR4 receptors, favouring the recovery of infected mice; further studies are needed to demonstrate this hypothesis.

This is the first report that identifies monomeric Ubiquitin as the major peptide component of an hDLE (Transferon), based on its relative ionization in MS and that it has a similar effect to the complete extract in a murine infection model when administered by the oropharyngeal route. Further, this work evinces that $\mathrm{Ub}$ can be used to develop oral immunomodulatory drugs.

\section{DATA AVAILABILITY STATEMENT}

The datasets presented in this study can be found in online repositories. The names of the repository/repositories and accession number(s) can be found in the article/ Supplementary Material.

\section{AUTHOR CONTRIBUTIONS}

LV-C, LP, and SP-T conceptualized the work. LF, SV-L, GM-S, ZM-P, LL-J, LV-F, and LV-C performed the assays and analyzed the results. LP and LV-C wrote the manuscript. EM-R provided critical assistance during this work. RC-S analyzed and interpreted data. All authors contributed to the article and approved the submitted version

\section{FUNDING}

The mass spectrometric analysis and the in vivo assays were performed using the equipment and facilities of "Laboratorio Nacional para Servicios Especializados de Investigacioín, Desarrollo e Innovacioín ( $+\mathrm{D}+\mathrm{i}$ ) para Farmoquimícos y Biotecnológicos" (LANSEIDI-FarBiotec-CONACyT), which is part of "Unidad de Desarrollo e Investigacioín en Bioprocesos (UDIBI)-IPN". All reagents and experimentation animals were provided by UDIBI (protocols FTU/DF/15/010-PRO, FTU/DF/ 16/004-PRO, FTU/P2/18/007-PRO, and UDIP20-013).

\section{ACKNOWLEDGMENTS}

First of all, the authors of this manuscript make a public reconnaissance of the work of Dr Sergio Estrada-Parra, a pioneer in the study of hDLE in Mexico and the teacher of several immunologist generations. In addition, LV-C thanks "Consejo Nacional de Ciencia y Tecnología" (CONACyT) for providing postgraduate fellowship (\#407865) during this work and to the chemist Ignacio Mejía Calvo (UDIBI-IPN, Mexico City) for his assistance during the execution of the murine model. The authors especially thank Brett S. Phinney and his team at the UCDavis Proteomics Core Facility who performed the sequencing analysis of Transferon peptides under a service contract.

\section{SUPPLEMENTARY MATERIAL}

The Supplementary Material for this article can be found online at: https://www.frontiersin.org/articles/10.3389/fphar.2020. 569039/full\#supplementary-material. 


\section{REFERENCES}

Animals, C. (2011). Guide for the care and use of laboratory animals. 8th ed (Washington DC: The National Academies Press), 246.

Azkargorta, M., Bregón-Villahoz, M., Escobes, I., Ibáñez-Pérez, J., Iloroa, I., Iglesias, M., et al. (2020). In-depth proteomics and natural peptidomics analyses reveal antibacterial peptides in human endometrial fluid. J. Proteomics 216, 103652. doi: 10.1016/j.jprot.2020.103652

Bertoni, M., Kiefer, F., Biasini, M., Bordoli, L., and Schwede, T. (2017). Modeling protein quaternary structure of homo- and hetero-oligomers beyond binary interactions by homology. Sci. Rep. 7 (1), 10480. doi: 10.1038/s41598-01709654-8

Bonaz, B., Sinniger, V., and Pellissier, S. (2016). Anti-inflammatory properties of the vagus nerve: potential therapeutic implications of vagus nerve stimulation. J. Physiol. 594 (20), 5781-5790. doi: 10.1113/JP271539

Breit, S., Kupferberg, A., Rogler, G., and Hasler, G. (2018). Vagus Nerve as Modulator of the Brain-Gut Axis in Psychiatric and Inflammatory Disorders. Front. Psychiatry 9, 44. doi: 10.3389/fpsyt.2018.00044

Browning, K. N., Verheijden, S., and Boeckxstaens, G. E. (2017). The Vagus Nerve in Appetite Regulation, Mood, and Intestinal Inflammation. Gastroenterology 152 (4), 730-744. doi: 10.1053/j.gastro.2016.10.046

Campos-Garcia, V. R., Herrera-Fernández, D., Espinosa-de la Garza, C. E., González, G., Vallejo-Castillo, L., Avila, S., et al. (2017). Process signatures in glatiramer acetate synthesis: structural and functional relationships. Sci. Rep. 7 (1), 12125. doi: 10.1038/s41598-017-12416-1

Cardoso, F. M., Tomkovaa, M., Petrovajova, D., Bubanova, M., Ragac, O., and Hornakova, T. (2017). New and cost effective cell-based assay for Dialyzed Leukocyte Extract (DLE)-induced Jurkat cells proliferation under azathioprine treatment. J. Pharm. BioMed. Anal. 138, 100-108. doi: 10.1016/j.jpba.2017.01.052

Castrejon Vazquez, M. I., Reséndiz-Albor, A. A., Ynga-Durand, M. A., Arciniega Martínez,, I. M., Orellana-Villazon, V. I., García López, C. A., et al. (2019). Dialyzable Leukocyte Extract (Transferon) Administration in Sepsis: Experience from a Single Referral Pediatric Intensive Care Unit. BioMed. Res. Int. 2019, 8980506. doi: 10.1155/2019/8980506

Crommelin, D. J. A., de Vlieger, J. S. B., and Mühlebach, S. (2015). "Introduction: Defining the Position of Non-Biological Complex Drugs," in Non-Biological Complex Drugs. The Science and the Regulatory Landscape. Eds. D. J. A. Crommelin and J. S. B. de Vlieger (New York: Springer), 1-3.

Estrada-Parra, S., Nagaya, A., Serrano, E., Rodriguez, O., Santamaria, V., Ondarza, R., et al. (1998). Comparative study of transfer factor and acyclovir in the treatment of herpes zoster. Int. J. Immunopharmacol. 20 (10), 521-535. doi: 10.1016/S01920561(98)00031-9

Fricker, L. D. (2015). Limitations of Mass Spectrometry-Based Peptidomic Approaches. J. Am. Soc. Mass Spectrom. 26 (12), 1981-1991. doi: 10.1007/ s13361-015-1231-x

Guex, N., Peitsch, M. C., and Schwede, T. (2009). Automated comparative protein structure modeling with SWISS-MODEL and Swiss-PdbViewer: a historical perspective. Electrophoresis 30 (Suppl 1), S162-S173. doi: 10.1002/elps.200900140

Hermann, G. E., Van Meter, M. J., and Rogers, R. C. (2008). CXCR4 receptors in the dorsal medulla: implications for autonomic dysfunction. Eur. J. Neurosci. 27 (4), 855-864. doi: 10.1111/j.1460-9568.2008.06058.x

Hernandez, M. E., Mendieta, D., Pérez-Tapia, M., Bojalil, R., Estrada-Garcia, I., EstradaParra, S., et al. (2013). Effect of selective serotonin reuptake inhibitors and immunomodulator on cytokines levels: an alternative therapy for patients with major depressive disorder. Clin. Dev. Immunol. 2013, 267871. doi: 10.1155/2013/ 267871

Hernandez-Esquivel, M. A., Pérez-Torres, A., Romero-Romero, L., Reyes-Matute, A., Loaiza, B., Mellado-Sánchez, G., et al. (2018). The dialyzable leukocyte extract Transferon(TM) inhibits tumor growth and brain metastasis in a murine model of prostate cancer. BioMed. Pharmacother. 101, 938-944. doi: 10.1016/ j.biopha.2018.03.012

Hodge, K., Have, S. T., Hutton, L., and Lamond, A. I. (2013). Cleaning up the masses: exclusion lists to reduce contamination with HPLC-MS/MS. J. Proteomics 88, 92-103. doi: 10.1016/j.jprot.2013.02.023

Homberg, T., Sáenz, V., Galicia-Carreón, J., Lara, I., Cervantes-Trujano, E., Andaluz, M. C., et al. (2015). The Adverse Event Profile in Patients Treated with Transferon (Dialyzable Leukocyte Extracts): A Preliminary Report. Pharmacol. Pharm. 6 (2015), 65-74.
Jaremko, L., Jaremko, M., Pasikowski, P., Cebrat, M., Stefanowicz, P., Lisowski, M., et al. (2009). The immunosuppressive activity and solution structures of ubiquitin fragments. Biopolymers 91 (6), 423-431. doi: 10.1002/bip. 21160

Jimenez-Uribe, A. P., Valencia-Martínez, H., Carballo-Uicab, G., Vallejo-Castillo, L., Medina-Rivero, E., Chacón-Salinas, R., et al. (2019). CD80 Expression Correlates with IL-6 Production in THP-1-Like Macrophages Costimulated with LPS and Dialyzable Leukocyte Extract (Transferon(R)). J. Immunol. Res. 2019, 2198508. doi: 10.1155/2019/2198508

Job, F., Settele, F., Lorey, S., Rundfeldt, C., Baumann, L., Beck-Sickinger, A. G., et al. (2015). Ubiquitin is a versatile scaffold protein for the generation of molecules with de novo binding and advantageous drug-like properties. FEBS Open Bio 5, 579-593. doi: 10.1016/j.fob.2015.07.002

Kirkpatrick, C. H. (2000). Transfer factors: identification of conserved sequences in transfer factor molecules. Mol. Med. 6 (4), 332-341. doi: 10.1007/BF03401941

Lawrence, H. S. (1949). The cellular transfer of cutaneous hypersensitivity to tuberculin in man. Proc. Soc. Exp. Biol. Med. 71 (4), 516-522.

Lee, S. K., and Ding, J. L. (2013). A perspective on the role of extracellular hemoglobin on the innate immune system. DNA Cell Biol. 32 (2), 36-40.

Majetschak, M. (2011). Extracellular ubiquitin: immune modulator and endogenous opponent of damage-associated molecular pattern molecules. J. Leukoc. Biol. 89 (2), 205-219.

Medina-Rivero, E., Merchand-Reyes, G., Pavón, L., Vázquez-Leyva, S., Pérez-Sánchez, G., Salinas-Jazmín, N., et al. (2014). Batch-to-batch reproducibility of Transferon. J. Pharm. BioMed. Anal. 88, 289-294. doi: 10.1016/j.jpba.2013.09.004

Medina-Rivero, E., Vallejo-Castillo, L., Vázquez-Leyva, S., Pérez-Sánchez, G., Favari, L., Velasco-Velázquez, M., et al. (2016). Physicochemical Characteristics of Transferon Batches. BioMed. Res. Int. 2016, 7935181.

Mellado-Sanchez, G., Lázaro-Rodríguez, J. J., Avila, S., Vallejo-Castillo, L., Vázquez-Leyva, S., Carballo-Uicab, G., et al. (2019). Development of Functional Antibodies Directed to Human Dialyzable Leukocyte Extract (Transferon(R)). J. Immunol. Res. 2019, 2754920. doi: 10.1155/2019/ 2754920

Ojeda, M. O., van't Veer, C., Fernández Ortega, C. B., Araña Rosainz, M. d. J., and Buurman, W. A. (2005). Dialyzable leukocyte extract differentially regulates the production of TNFalpha, IL-6, and IL-8 in bacterial component-activated leukocytes and endothelial cells. Inflamm. Res. 54 (2), 74-81. doi: 10.1007/ s00011-004-1326-5

Patel, M. B., Proctor, K. G., and Majetschak, M. (2006). Extracellular ubiquitin increases in packed red blood cell units during storage. J. Surg. Res. 135 (2), 226-232.

Pavlov, V. A., and Tracey, K. J. (2012). The vagus nerve and the inflammatory reflexlinking immunity and metabolism. Nat. Rev. Endocrinol. 8 (12), 743-754.

Pavlov, V. A., and Tracey, K. J. (2017). Neural regulation of immunity: molecular mechanisms and clinical translation. Nat. Neurosci. 20 (2), 156-166.

Plow, E. F., and Edgington, T. S. (1986). Lymphocyte suppressive peptides from fibrinogen are derived predominantly from the A alpha chain. J. Immunol. 137 (6), 1910-1915.

Pourjoula, M., Picariello, G., Garro, G., D'Auria, G., Nitride, C., Ghaisari, R., et al. (2020). The protein and peptide fractions of kashk, a traditional Middle East fermented dairy product. Food Res. Int. 132, 109107. doi: 10.1016/ j.foodres.2020.109107

Qiu, P., Wheater, M. K., Qiu, Y., and Sosne, G. (2011). Thymosin beta4 inhibits TNF-alpha-induced NF-kappaB activation, IL-8 expression, and the sensitizing effects by its partners PINCH-1 and ILK. FASEB J. 25 (6), 1815-1826. doi: 10.1096/fj.10-167940

Ramirez-Ramirez, D., Vadillo, E., Arriaga-Pizano, L. A., Mayani, H., EstradaParra, S., Velasco-Velázquez, M. A., et al. (2016). Early Differentiation of Human CD11c(+)NK Cells with gammadelta T Cell Activation Properties Is Promoted by Dialyzable Leukocyte Extracts. J. Immunol. Res. 2016, 4097642. doi: $10.1155 / 2016 / 4097642$

Saini, V., Marchese, A., Tang, W.-J., and Majetschak, M. (2011). Structural determinants of ubiquitin-CXC chemokine receptor 4 interaction. J. Biol. Chem. 286 (51), 44145-44152. doi: 10.1074/jbc.M111.298505

Salinas-Jazmin, N., Estrada-Parra, S., Becerril-García, M. A., Limón-Flores, A. Y., Vázquez-Leyva, S., Medina-Rivero, E., et al. (2015). Herpes murine model as a biological assay to test dialyzable leukocyte extracts activity. J. Immunol. Res. 2015, 146305. doi: $10.1155 / 2015 / 146305$ 
Santacruz-Valdes, C., Aguilar, G., Estrada-Parra, S., Perez-Tapia, M., and JimenezMartinez, M. C. (2010). Dialyzable leukocyte extracts (transfer factor) as adjuvant therapy for fungal keratitis. Am. J. Case Rep. 11 (2010), 97-101.

Schrader, M. (2018). "Origins, Technological Development, and Applications of Peptidomics," in Peptidomics, Methods and Strategies. Eds. M. Schrader and L. D. Fricker (UK: Humana Press).

Scofield, S. L. C., Dalal, S., Lim, K. A., Thrasher, P. R., Daniels, C .R., Peterson, J. M., et al. (2019). Exogenous ubiquitin reduces inflammatory response and preserves myocardial function 3 days post-ischemia-reperfusion injury. Am. J. Physiol. Heart Circ. Physiol. 316 (3), H617-H628.

Secretaría de Agricultura, G. (1999). "Desarrollo Rural, Pesca y Alimentación, Especificaciones técnicas para la producción, cuidado y uso de los animales de laboratorio," in NOM-062-ZOO-1999 (Mexico City: DOF), 58.

Sloper-Mould, K. E., Jemc, J. C., Pickart, C. M., and Hicke, L. (2001). Distinct functional surface regions on ubiquitin. J. Biol. Chem. 276 (32), 30483-30489. doi: $10.1074 /$ jbc.M103248200

Takada, K., Nasu, H., Hibi, N., Tsukada, Y., Shibasaki, T., Fujise, K., et al. (1997). Serum concentrations of free ubiquitin and multiubiquitin chains. Clin. Chem. 43 (7), 1188-1195. doi: 10.1093/clinchem/43.7.1188

Tulina, D., Chan, M. K. S., Michele, W. B. F., and Pan, S. Y. (2019). Transfer Factors or Dialyzable leukocyte Extracts as Immunomodulating Peptides: A Conceptual Review on Broad Spectrum of Therapeutic Areas, Immunologic and Clinical Responses, Trends and Perspectives. Int. J. Immunol. Immunother. 6 (1), 6. doi: 10.23937/2378-3672/1410039

Vazquez-Leyva, S., Vallejo-Castillo, L., López-Morales, C. A., Herbert-Pucheta, J. E., Zepeda-Vallejo, L. G., Velasco-Velázquez, M., et al. (2019). Identity Profiling of Complex Mixtures of Peptide Products by Structural and Mass Mobility Orthogonal Analysis. Anal. Chem. 91 (22), 14392-14400.

Vignesh, P., Rawat, A., Sharma, M., and Singh, S. (2017). Complement in autoimmune diseases. Clin. Chim. Acta 465, 123-130. doi: 10.1016/ j.cca.2016.12.017
Zhou, J., Kong, C., Yuan, Z., Luo, J., Ma, R., Yu, J., et al. (2013). Preparation, characterization, and determination of immunological activities of transfer factor specific to human sperm antigen. BioMed. Res. Int. 2013, 126923.

Conflict of Interest: SP-T is involved in the development and commercialization of Transferon.

The remaining authors declare that the research was conducted in the absence of any commercial or financial relationships that could be construed as a potential conflict of interest.

The reviewer EZ declared a past co-authorship with one of the authors LP to the handling editor.

Citation: Vallejo-Castillo L, Favari L, Vázquez-Leyva S, Mellado-Sánchez G, Macias-Palacios Z, López-Juárez LE, Valencia-Flores L, Medina-Rivero E,

Chacón-Salinas R, Pavón L and Pérez-Tapia SM (2020) Sequencing Analysis and Identification of the Primary Peptide Component of the Dialyzable Leukocyte Extract "Transferon Oral": The Starting Point to Understand Its Mechanism of Action.

Front. Pharmacol. 11:569039. doi: 10.3389/fphar.2020.569039

Copyright (C) 2020 Vallejo-Castillo, Favari, Vázquez-Leyva, Mellado-Sánchez, Macias-Palacios, López-Juárez, Valencia-Flores, Medina-Rivero, Chacón-Salinas, Pavón and Pérez-Tapia. This is an open-access article distributed under the terms of the Creative Commons Attribution License (CC BY). The use, distribution or reproduction in other forums is permitted, provided the original author(s) and the copyright owner(s) are credited and that the original publication in this journal is cited, in accordance with accepted academic practice. No use, distribution or reproduction is permitted which does not comply with these terms. 